\title{
Numerical Modelling of Cuttings Transport with Foam in Inclined Wells
}

\author{
O. Osunde and E. Kuru*
}

School of Mining and Petroleum Engineering, The University of Alberta, Canada

\begin{abstract}
In this study, a 1-D transient state mechanistic model of cuttings transport with foam in inclined wells has been developed. The model is solved numerically to predict the optimum foam flow rate (liquid and gas rate) and rheological properties that would maximize cuttings transport efficiency in inclined wells. A detailed sensitivity analysis of the effect of gas and liquid flow rates, drilling rate, foam rheological properties, borehole geometry, wellbore inclination and the rate of gas and liquid influx from the reservoir on the cutting transport efficiency was presented. The cuttings transport efficiency decreases with increase in well inclination from the vertical under the same flow condition. Cuttings are transported more efficiently at higher gas injection rates. The influx of gas from reservoir into the wellbore has a positive effect on the cutting transport process whereas water influx has the reverse effect. The time required for achieving stabilized bottomhole pressure increases with increasing drilling rate and with increasing inclination of the well from the vertical position. The distribution of cuttings along the annulus is found to be not uniform, even under the steady state flow condition. The highest concentration of cuttings is always at the bottom of the hole and the lowest is at the top.
\end{abstract}

\section{INTRODUCTION}

The term underbalanced drilling (UBD) refers to a drilling operation in which the pressure of the drilling fluid is designed to be lower than the pressure of the formation [1]. Underbalanced drilling is designed such that an underbalanced drilling condition is achieved throughout the entire drilling and completion operation [2].

Field applications have proven that UBD techniques have many advantages including minimized formation damage, increased drilling rate, improved formation evaluation while drilling, minimized lost circulation, reduced occurrence of differential pipe and logging tools sticking, enhanced detection of all producing zones, and enhanced earlier production from reservoir [3-11].

Based on the type of drilling fluids used, underbalanced drilling operation can be classified into four categories [12]. Air/gas drilling, gasified liquid drilling, foam drilling and the flow drilling, which involves using fluids with density below the formation's hydrostatic pressure gradient.

Foam as a drilling fluid is commonly used for underbalanced drilling because of its low variable density which makes adjustment of foam density possible in order to keep control of the circulating bottomhole pressure and its high effective viscosity which gives a superior cuttings lifting and transport ability. Apart from having a good lifting ability and the ability to maintain an underbalanced drilling condition, foam is also used to remove formation fluids that enter the borehole while drilling and also serve as an insulating medium if loss circulation is a problem. Applications of foam as a drilling fluid in many drilling operations, and the results from various field cases are well documented [13-24].

*Address correspondence to this author at the School of Mining and Petroleum Engineering, The University of Alberta, Canada;

E-mail: ekuru@ualberta.ca
In this paper, a transient mechanistic model is presented for the prediction of foam drilling performance in inclined wells. The new model considers foam rheological properties, drag coefficient of cuttings in foam, formation fluid influx, drillpipe eccentricity, inclination effect and drilling rate and thereby provides an effective numerical solution method to simulate the hydraulics of foam drilling in inclined wells.

\section{BACKGROUND}

Problems associated with inefficient cutting transport are; reduction in penetration rate, wear of bit, pipe stuck, high torque and drag and other hole problems [25-29]. The elimination or minimization of these problems associated with ineffective cuttings transport requires proper understanding of the cuttings transport mechanism.

Experimental studies have shown that well inclination angle, borehole geometry, rotation of drill pipe, drill pipe eccentricity, drilling rate, cuttings size, flow rate, fluid velocity, mud type, mud rheology and flow regime are some of the most important parameters which control the cuttings transport process [30-43]. Based on these experimental studies, empirical models were developed [44-49] and rules of thumb for field practices were also suggested [50-52]. Mechanistic models of cuttings transport were also developed [53-62].

\section{Cuttings Transport with Foam}

Krug and Mitchell [63] developed charts for the determination of minimum volume of liquid and gas and the injection-pressure required for foam drilling operation.

Okpobiri and Ikoku [64] used an iterative approach to develop a procedure for the determination of the minimum velocity of foam to be injected and at what wellhead injection pressure this should be done to ensure effective cuttings transport. In their study foam-cutting flow was assumed homogeneous and suggested that for effective cuttings trans- 
port, the fluid velocity at the bottom should be at least $10 \%$ higher than the terminal velocity at the same depth.

Owayed [65] developed a 1-D steady state model similar to that of Okpobiri and Ikoku [64], but unlike the latter he accounted for reservoir influx (water) in his model.

Li [66] developed a 1-D transient model for cuttings transport with foam in vertical and horizontal wells.

Guo et al. [67] developed an analytic model that can be used to calculate bottomhole pressure when drilling with foam in deviated wells. Their model was similar to that of Okpobiri and Ikoku's [64] model except for the fact that solid friction factor of the cuttings was not taken into account. For this reason, the bottomhole pressure predicted by Guo et al. approach was lower than that predicted by the Okpobiri and Ikoku's method.

In all these previous models, authors assumed homogeneous flow of cuttings and foam with exception of that developed by Li [66]. The assumption of no slip between cuttings and foam imply that the drag force is infinite which results in over-estimation of the solid carrying capacity of foam.

In this study, a transient 1-D mechanistic model is developed to study cuttings transport with foam in inclined wells. The model considered the slippage between the cuttings and foam. The model predictions were verified by using the experimental results from Tulsa University Drilling research program. The model was used to demonstrate how different factors would affect the cuttings transport efficiency with foam. The following section explains the development of the model used in this study.

\section{MODEL DEVELOPMENT}

In this study a two layer model is developed to investigate the cuttings transport with foam in inclined well. The upper layer is made of foam with suspended cuttings with a low solid concentration and the lower layer a bed of solid cuttings which is either stationary or moving. This approach has been originally used for modeling of slurry transport in pipes [68-70]. Several studies in petroleum drilling engineering on cuttings transport modeling have also used the twolayer modeling approach [54-62].

\section{Geometry of the Cuttings Transport Model}

The two layer model is composed of an upper heterogeneous layer (Fig. 1) which is made of cuttings (the disperse phase) suspended in foam (the continuous phase). Below this layer is the cuttings bed layer which is made of particles that are cubically packed with a particle concentration of 0.52 .

The upper layer has a cross sectional area denoted by $\mathrm{A}_{2}$ and two wetted perimeters; the first one is along with the drill pipe (arc GHF) and the second one is along with the wellbore ( $\operatorname{arc} \mathrm{CKD})$. The sum of these two wetted perimeters gives the total wetted perimeter for the upper layer $\left(\mathrm{S}_{\mathrm{s}-\mathrm{w}}\right.$ or $\left.\mathrm{S}_{\mathrm{f}-\mathrm{w}}\right)$.

Similarly, the lower cuttings bed layer has a cross sectional area of $A_{1}$ and two wetted perimeters; the first one is along with the drill pipe (arc GIF) and the second one is along with the wellbore (arc CED), which sums up to give the total wetted perimeter for the lower layer represented as
$\mathrm{S}_{\mathrm{B}-\mathrm{w}}$. The wetted perimeter between the upper and the lower layers is represented by $S_{\mathrm{i}}$ (length CG plus length FD).
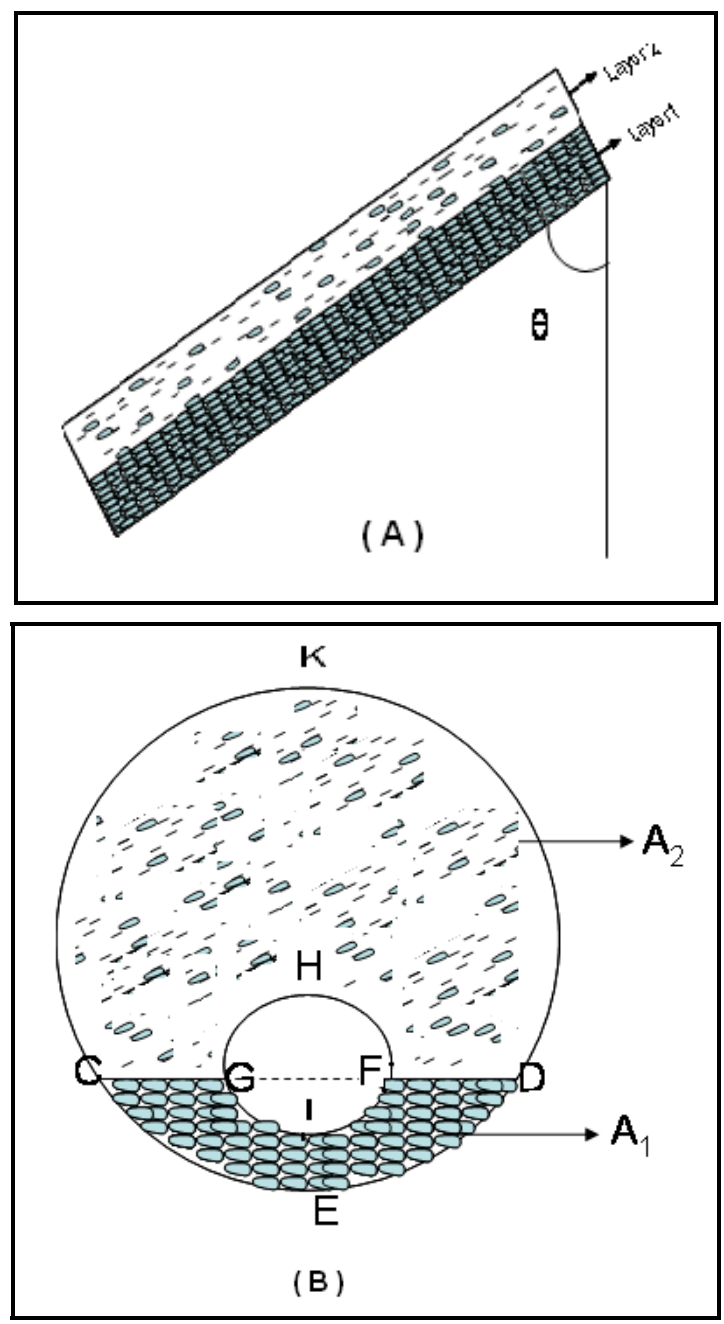

Fig. (1). Schematic view of two-Layer model for cuttings transport with foam in inclined wells: (A) Side view (B) Cross-sectional view.

\section{Assumptions of the Cuttings Transport Model}

The following assumptions are made for the development of the foam drilling model in inclined wells:

(1) Foam is considered as a homogeneous nonNewtonian fluid whose rheology can be represented by a power law model.

(2) The cuttings are assumed to be spherical with uniform sizes, shape and velocity at any cross-sectional area of the well.

(3) The reservoir influx fluids commingle with the drilling foam completely.

(4) Inflowing reservoir fluids accelerate to the mean stream velocity instantaneously.

(5) Slippage exists between the foam and cuttings.

\section{Continuity and Momentum Equations}

Equations (1), (2) and (3) are the continuity equations representing conservation of mass for suspended solids, foam and cuttings bed respectively. 


$$
\begin{aligned}
& \frac{\partial\left(A_{2} \rho_{s} C_{s}\right)}{\partial t}+\frac{\partial\left(A_{2} \rho_{s} u_{s} C_{s}\right)}{\partial s}=A_{2} \Delta s_{s} \\
& \frac{\partial\left(A_{2} \rho_{f} C_{f}\right)}{\partial t}+\frac{\partial\left(A_{2} \rho_{f} u_{f} C_{f}\right)}{\partial s}=A_{2}\left(s_{f}+\Delta s_{f}\right) \\
& \frac{\partial\left(A_{1} \rho_{1}\right)}{\partial t}+\frac{\partial\left(A_{1} \rho_{1} u_{1}\right)}{\partial s}=A_{1} \Delta s_{1}
\end{aligned}
$$

$\Delta s_{s}, \Delta s_{f}$ and $\Delta s_{1}$ represent the rates of change of mass of suspended solids, foam and the cuttings bed per unit volume of the wellbore due to the mass transfer between layers.:

$\Delta s_{s}, \Delta s_{f}$ and $\Delta s_{1}$ can be determined by using Equation (4), (5) and (6) respectively.

$\Delta s_{s}=\frac{-\rho_{s} V_{D} C_{s} S_{i}+\rho_{s} V_{E} C_{b} S_{i}}{A_{2}}$

$\Delta s_{f}=\frac{-\frac{C_{f 1}}{C_{b}} \rho_{f} \cdot C_{s} V_{D} S_{i}+\rho_{f} V_{E} C_{f 1} S_{i}}{A_{2}}$

$\Delta s_{1}=\left(\rho_{s}+\frac{C_{f 1}}{C_{b}} \rho_{f}\right) \cdot C_{s} V_{D} \frac{S_{i}}{A_{1}}-\rho_{1} V_{E} \frac{S_{i}}{A_{1}}$

Equations (7), (8) and (9) are conservation of momentum equations for suspended solids, foam and cuttings bed respectively.

$$
\begin{aligned}
& \frac{\partial\left(C_{s} \rho_{s} u_{s}^{2}\right)}{\partial s}+\frac{\partial\left(C_{s} \rho_{s} u_{s}\right)}{\partial t}= \\
& -C_{s} \frac{\partial p}{\partial s}-C_{s} \rho_{s} g \operatorname{Cos} \theta-\frac{1}{2} C_{s} f_{s} \rho_{s} u_{s}^{2} \frac{S_{2}}{A_{2}}- \\
& \frac{1}{2} C_{s} f_{s} \rho_{s}\left(u_{s}-u_{1}\right)^{2} \frac{S_{i}}{A_{2}}+\frac{3 C_{s}}{4 d_{s}} \rho_{f} C_{D}\left(u_{f}-u_{s}\right)^{2} \\
& +u_{1} v_{e n t} C_{b} \rho_{s} \frac{S_{i}}{A_{2}} \operatorname{Cos} \theta-u_{s} v_{D} C_{s} \rho_{s} \frac{S_{i}}{A_{2}} \operatorname{Cos} \theta \\
& \frac{\partial\left(C_{f} \rho_{f} u_{f}^{2}\right)}{\partial s}+\frac{\partial\left(C_{f} \rho_{f} u_{f}\right)}{\partial t}= \\
& -C_{f} \frac{\partial p}{\partial s}-C_{f} \rho_{f} g \operatorname{Cos} \theta-\frac{1}{2} C_{f} f_{f} \rho_{f} u_{f}^{2} \frac{S_{f-w}}{A_{2}}- \\
& \frac{1}{2} C_{f} f_{f} \rho_{f}\left(u_{f}-u_{1}\right)^{2} \frac{S_{i}}{A_{2}}-\frac{3 C_{s}}{4 d_{s}} \rho_{f} C_{D}\left(u_{f}-u_{s}\right)^{2} \\
& +u_{1} v_{e} C_{f 1} \rho_{f} \frac{S_{i}}{A_{2}} \operatorname{Cos} \theta-u_{f} v_{D} \frac{C_{f 1}}{C_{b}} C_{s} \rho_{f} \frac{S_{i}}{A_{2}} \operatorname{Cos} \theta \\
& \frac{\partial\left(\rho_{1} u_{1}^{2}\right)}{\partial s}+\frac{\partial\left(\rho_{1} u_{1}\right)}{\partial t}= \\
& -\frac{\partial p}{\partial s}-\rho_{1} g \operatorname{Cos} \theta+\frac{1}{2} c_{f} f_{f} \rho_{f}\left(u_{f}-u_{1}\right)^{2} \frac{S_{B-i}}{A_{1}}+ \\
& \frac{1}{2} c_{s} f_{s} \rho_{s}\left(u_{s}-u_{1}\right)^{2} \frac{S_{B-i}}{A_{1}}-\frac{1}{2} f_{B-w} \rho_{1} u_{1}^{2} \frac{S_{B-w}}{A_{1}}+ \\
& \left(u_{s} v_{D} C_{s} \rho_{s} \frac{S_{i}}{A_{1}}+u_{f} v_{D} \frac{C_{f 1}}{C_{b}} C_{s} \rho_{f} \frac{S_{i}}{A_{1}}-u_{1} v_{E} \rho_{1} \frac{S_{i}}{A_{1}}\right) \\
& \operatorname{Cos} \theta-\frac{F_{1}}{A_{1} \Delta s}
\end{aligned}
$$

The foam flow rate in the upper layer would be affected by fluid influx from the reservoir due to the underbalanced drilling condition. The mass influx rate of water, oil and gas from the reservoir per unit volume of the wellbore can be determined using equations (10) to (12) respectively.

$$
\begin{aligned}
s_{w} & =\frac{\rho_{w} P I_{w}\left(P_{r e}-P\right)}{A_{2}} \\
s_{o} & =\frac{\rho_{o} P I_{o}\left(P_{r e}-P\right)}{A_{2}} \\
s_{g} & =\frac{\rho_{g} P I_{g}\left(P_{r e}-P\right)}{A_{2}}
\end{aligned}
$$

PI is the specific productivity index; this is the volumetric inflow rate of fluid from the reservoir into the wellbore per unit pressure drop between the reservoir and the wellbore per unit length. The total mass influx from the formation into the wellbore is given by equation (13)

$$
s_{f}=s_{w}+s_{o}+s_{g}
$$

Equations (7) and (8) can be added together to eliminate the drag force between solids and the foam in the upper layer.

$$
\begin{aligned}
& \frac{\partial\left(C_{s} \rho_{s} u_{s}^{2}+C_{f} \rho_{f} u_{f}^{2}\right)}{\partial s}+\frac{\partial\left(C_{s} \rho_{s} u_{s}+C_{f} \rho_{f} u_{f}\right)}{\partial t}= \\
& -\frac{\partial p}{\partial s}-\left(C_{s} \rho_{s}+C_{f} \rho_{f}\right) g \operatorname{Cos} \theta-\frac{1}{2} c_{f} f_{f} \rho_{f} u_{f}^{2} \frac{S_{2}}{A_{2}} \\
& -\frac{1}{2} c_{s} f_{s} \rho_{s} u_{s}^{2} \frac{S_{2}}{A_{2}}-\frac{1}{2} c_{f} f_{f} \rho_{f}\left(u_{f}-u_{1}\right)^{2} \frac{S_{i}}{A_{2}} \\
& -\frac{1}{2} c_{s} f_{s} \rho_{s}\left(u_{s}-u_{1}\right)^{2} \frac{S_{i}}{A_{2}}+u_{1} v_{E} \frac{S_{i}}{A_{2}} \rho_{1} \operatorname{Cos} \theta \\
& -\left(u_{s} \rho_{s}+\frac{C_{f 1}}{C_{b}} u_{f} \rho_{f}\right) v_{D} C_{s} \frac{S_{i}}{A_{2}} \operatorname{Cos} \theta
\end{aligned}
$$

Under steady state flow condition, neglecting the acceleration term and material exchange terms (between layers) equation (14) would reduce to

$$
\begin{aligned}
& \frac{\partial p}{\partial s}=-\left(C_{s} \rho_{s}+C_{f} \rho_{f}\right) g \operatorname{Cos} \theta-\frac{1}{2} c_{f} f_{f} \rho_{f} u_{f}^{2} \frac{S_{2}}{A_{2}}- \\
& \frac{1}{2} c_{s} f_{s} \rho_{s} u_{s}^{2} \frac{S_{2}}{A_{2}}-\frac{1}{2} c_{f} f_{f} \rho_{f}\left(u_{f}-u_{1}\right)^{2} \frac{S_{i}}{A_{2}}- \\
& \frac{1}{2} c_{s} f_{s} \rho_{s}\left(u_{s}-u_{1}\right)^{2} \frac{S_{i}}{A_{2}}
\end{aligned}
$$

As seen from equation (15), the steady state pressure drop for the model in the upper layer consist of the two parts; the hydrostatic pressure drop due to suspension, the frictional pressure drop due to the suspension (foam and suspended solids) and the relative motion between the upper and the lower layer if a bed is formed. Other closure equations are presented in the Appendix A.

\section{BOUNDARY CONDITIONS}

The gas and liquid injection rates must be specified. Drilling rate should also be specified so that the mass flow rate of the cuttings in the annulus can be calculated. Finally, back pressure specified at the exit of the pipe. 


\section{INITIAL CONDITIONS}

Stable foam flow condition is assumed to be achieved before the drilling begins. The pressure and velocity distribution, and properties of foam are calculated and set as the initial condition of the flow model.

\section{METHOD OF SOLUTION}

In this paper, the Crowe's [71] method for two phase flow which is a modification of the numerical solution scheme called SIMPLE developed by Patankar [72] for single phase flow was employed with some modification to facilitate the convergence of the numerical solution. This technique was also used by $\mathrm{Li}$ [66] in the development of his model for cuttings transport with foam in horizontal wells.

\section{VERIFICATION OF THE MODEL}

The model predictions were compared with the experimental data collected from the LPAT flow loop facility at the University of Tulsa by Capo [73]. The input data used for the comparison study are given in Table $\mathbf{1}$.

The results of the comparison of model predictions with experimental data are shown in Table 2. It was seen that numerical method under predicted the pressure drop observed during cuttings transport experiments conducted in $45^{\circ}$ inclination well. The difference between measured and calculated pressure value varied between 4.6 to $21.6 \%$.

Table 1. Input Data used for Model Verification Study

\begin{tabular}{|c|c|}
\hline Length of inclined wells(ft) & 90 \\
\hline Diameter of hole(in) & 8.0 \\
\hline Outer diameter of pipe(in) & 4.5 \\
\hline Cutting size $(\mathrm{cm})$ & 2.311 \\
\hline Density of cuttings $\left(\mathrm{g} / \mathrm{cm}^{3}\right)$ & 2.613 \\
\hline Back pressure $(\mathrm{psi})$ & 14.7 \\
\hline Nozzle diameter (in) & $28 / 32$ \\
\hline Inclination of well(degree) & 45 \\
\hline
\end{tabular}

\section{SENSITIVITY ANALYSES OF THE FACTORS AFFECTING CUTTINGS TRANSPORT}

The sensitivity analyses were conducted to show effects of gas and liquid injection rates, drilling rate, reservoir influx and inclination on the bottomhole pressure and cuttings concentration profile. The base data used for the simulation are shown in Table $\mathbf{3}$.

\section{Effect of Gas Injection Rate on Bottomhole Pressure and Cuttings Concentration}

Figs. $(\mathbf{2}, \mathbf{3})$ illustrate the effect of gas injection rate on the cuttings concentration and bottomhole pressure respectively. The gas injection rate has significant effect on the cuttings transport process. Fig. (2) shows that increasing the gas injection rate results to a better cutting transport reflected by reduction in the average cuttings concentration in the annulus. Increased gas flow rate increases foam quality, which in turn increases the effective viscosity of the foam and the cuttings lifting capacity of the foam. The effect of gas injection rate is more pronounced at lower gas injection rates.

As shown in Fig. (3), the bottomhole pressure decreases as gas injection rate increases. This is because increasing the gas rate reduces the density of foam which in turn decreases the hydrostatic pressure hence reducing the bottomhole pressure.

The reduction in bottomhole pressure can also be explained in terms of reduction in average cuttings concentration in the annulus with increase in the gas injection rate. The hydrostatic pressure has significant effect on the bottomhole pressure when the foam flow rate is not too high.

\section{Effect of Liquid Injection Rate on Bottomhole Pressure and Cuttings Concentration}

The effect of liquid injection rate on average cuttings concentration and bottomhole pressure is also illustrated by Figs. (2,3). As shown in Fig. (2), liquid injection rate has little influence on the cuttings concentration compared to the effect of gas injection rate. Results also indicate that at very low or very high gas injection rate, the effect of increase in liquid rate has negligible effect on the cuttings concentration. Increasing liquid injection rates increases the bottomhole pressure but reduces the foam quality which reduces the effective viscosity and therefore, lifting and transport ability of foam is reduced. Fig. (3) shows that the bottomhole pressure increases with the increasing liquid injection rate. As the liquid injection rates reduces the foam quality (increase in foam density) which in turns increases the hydrostatic pressure. This increase in bottomhole pressure can also be explained in terms of increase in cuttings accumulation associated with increase in the liquid injection rate which increases the foam-cuttings density in the annulus.

\section{Effect of Drilling rate on Bottomhole Pressure and Cut- tings Concentration}

Figs. (4,5) illustrate the effect of drilling rate on the cuttings concentration and bottomhole pressure respectively.

Table 2. Comparison of Model Predictions with Experimental Results

\begin{tabular}{|c|c|c|c|c|c|c|}
\hline Test & Qair scfm & Qliq gpm & ROP ft/hr & $\Delta \mathbf{P}($ Exp.) psia & $\Delta$ P (Model) psia & \% Error \\
\hline \hline 1 & 60 & 108 & 59.9 & 26.85 & 25.6 & 26.1 \\
\hline 2 & 80 & 120 & 32.5 & 30.99 & 27.3 & 15.8 \\
\hline 3 & 35 & 96 & 27.7 & 22.44 & 21.6 \\
\hline 4 & 135 & 64 & 86.6 & 32.70 & 28.0 & 14.4 \\
\hline
\end{tabular}


For fixed gas and liquid injection rates, bottomhole pressures increases with increasing drilling rate. This effect is attributed to increase in the average cutting concentration in the annulus with increasing drilling rate as shown in Fig. (5).

Table 3. Base Data Used for Simulation of Foam Drilling in Inclined Wells

\begin{tabular}{|c|c|}
\hline Back Pressure & 40 psia \\
\hline Reservoir Pressure & 500 psia \\
\hline Time Increment & $60 \mathrm{sec}$ \\
\hline Number of Control volume & 30 \\
\hline Length of inclined well & $400 \mathrm{ft}$ \\
\hline Hole Diameter & $8.5 \mathrm{in}$ \\
\hline Drill Pipe OD & $4.5 \mathrm{in}$ \\
\hline Drill Pipe ID & 3.826 in \\
\hline Eccentricity & 1.0 \\
\hline Cutting Size & 0.5 in \\
\hline Cutting specific gravity & 2.7 \\
\hline Bit nozzle size (3 nozzles) & $28 / 32$ in \\
\hline Surface temperature & $60^{\circ} \mathrm{F}$ \\
\hline Geothermal gradient & $1.5^{0} \mathrm{~F} / 100 \mathrm{ft}$ \\
\hline Foam & Air + water \\
\hline Drilling rate & $60 \mathrm{ft} / \mathrm{hr}$ \\
\hline Gas injection rate & $40 \mathrm{scfm}$ \\
\hline Liquid Injection rate & $40 \mathrm{gpm}$ \\
\hline Gas specific PI & $0 \mathrm{scfm} / \mathrm{ft} / \mathrm{psia}$ \\
\hline Water specific PI & $0 \mathrm{gpm} / \mathrm{ft} / \mathrm{psia}$ \\
\hline Oil specific PI & $0 \mathrm{gpm} / \mathrm{ft} / \mathrm{psia}$ \\
\hline Inclination & $30 \mathrm{deg}$ \\
\hline Thickness of reservoir & $100 \mathrm{ft}$ \\
\hline
\end{tabular}

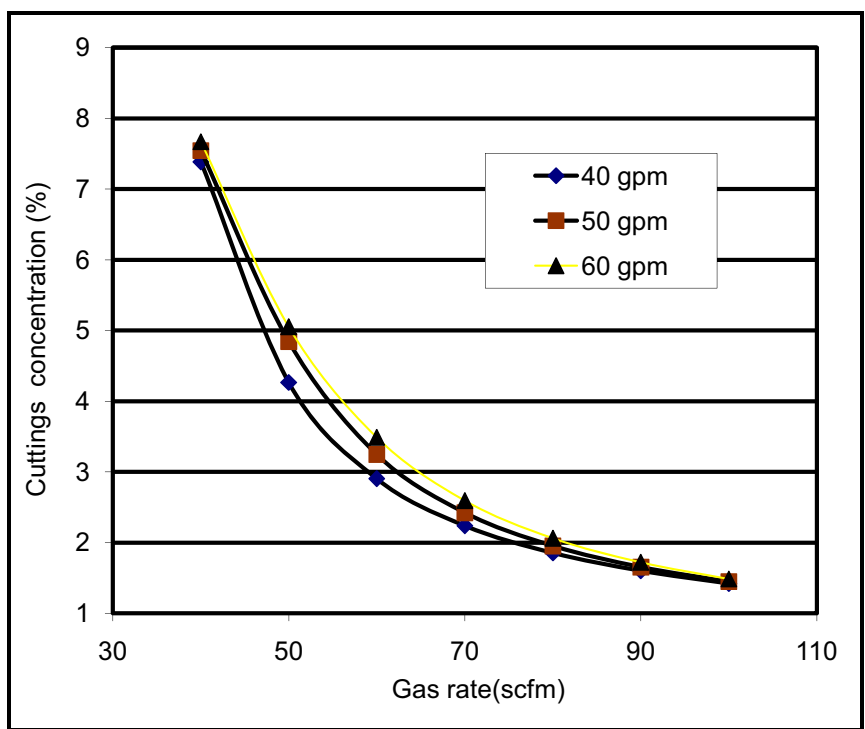

Fig. (2). Average cuttings concentration variation with gas and liquid injection rate.

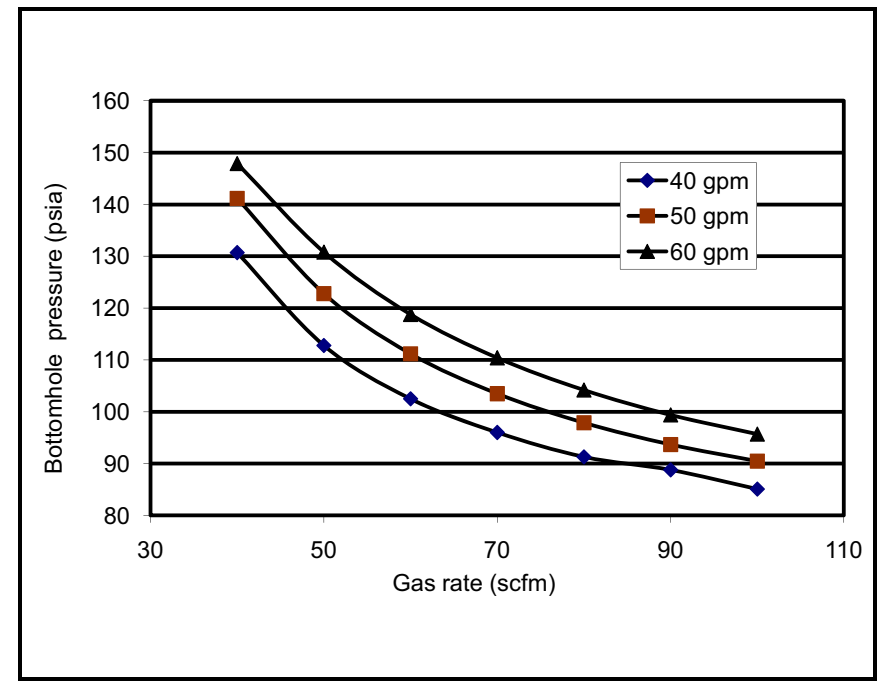

Fig. (3). Bottomhole pressure variation with gas and liquid injection rate.

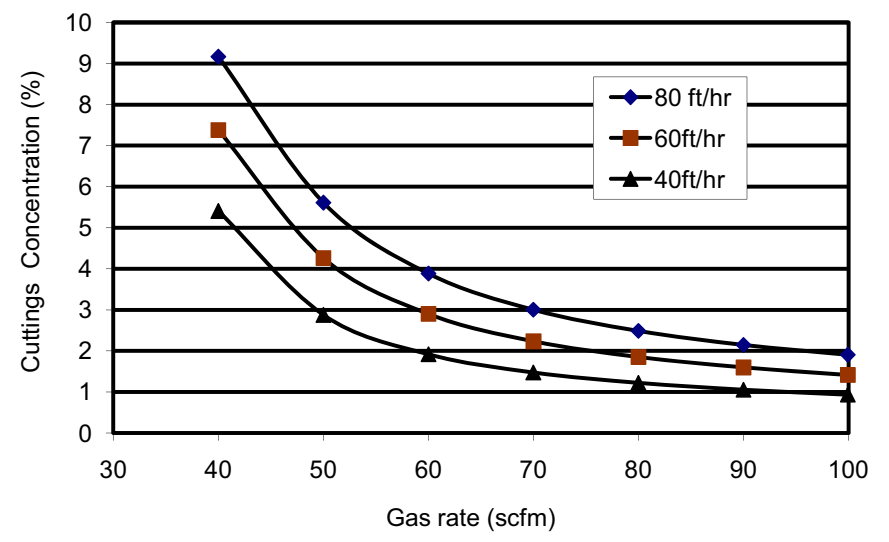

Fig. (4). Average cuttings concentration variation with drilling rate.

The effect of drilling rate on the cuttings concentration is more pronounced at lower gas rates. The increase in cuttings concentration in the annulus with increase in drilling rate is responsible for the increase in the bottomhole pressure as shown in Fig. (5).

\section{Effect of Inclination on Bottomhole Pressure and Cut- tings Concentration}

Figs. (6-8) illustrate the effect of well inclination on the cuttings concentration and the bottomhole pressure in the annulus. The cuttings concentration increases as inclination angle of the well from the vertical increases for fixed gas and liquid injection rates (Fig. 6).

Fig. (8) indicates that to keep the cuttings concentration in the annulus constant (at 2\%) more gas needs to be injected as the inclination from the vertical increases.

Fig. (9) shows the distribution of cuttings along the well at steady state flow condition for different angle of inclinations. For all angles of inclinations, the highest cuttings concentration was always observed at the bottom and the lowest cuttings concentration was always at the top of the well. 


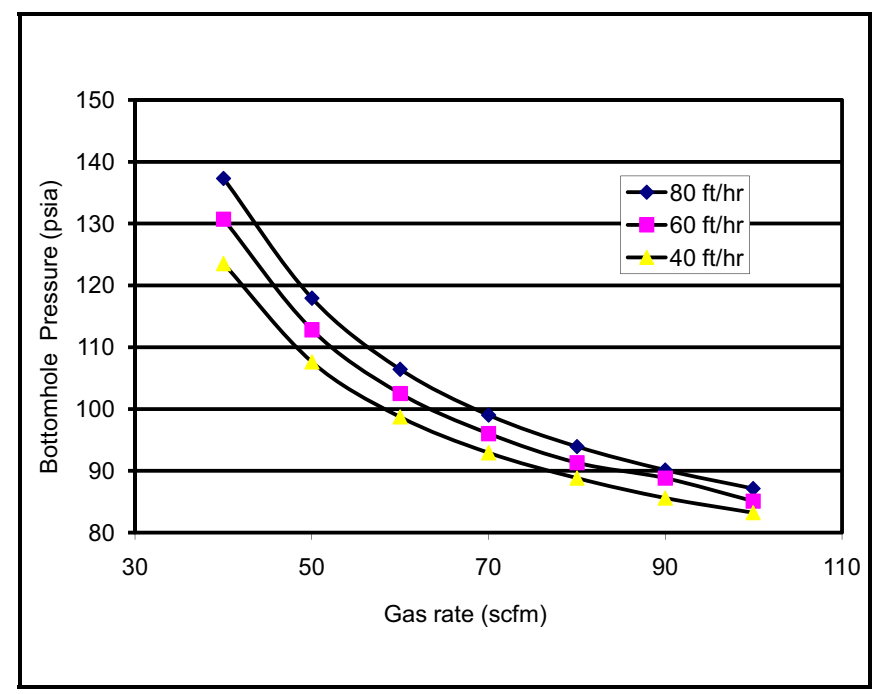

Fig. (5). Bottomhole pressure variation with drilling rate.

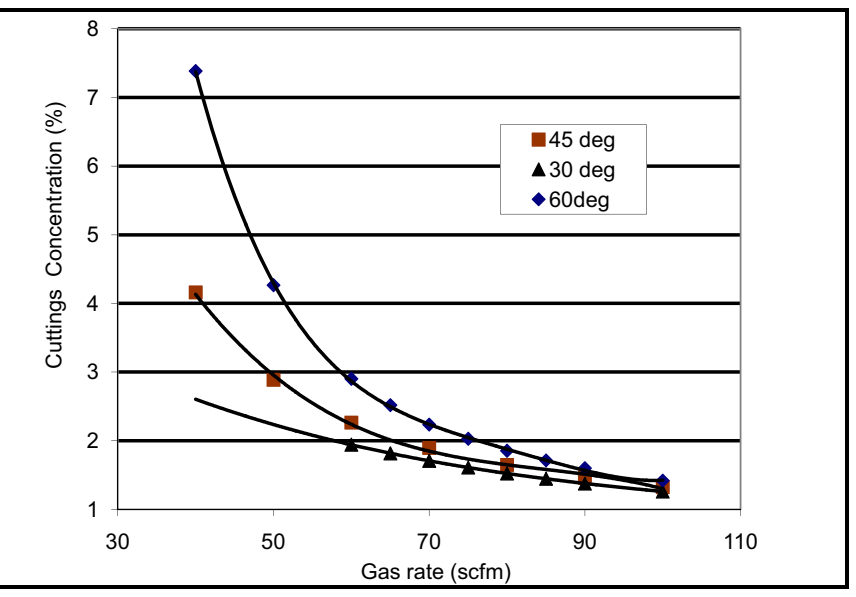

Fig. (6). Average cuttings concentration variation with inclination.

Fig. (7) depicts that an increase in the bottomhole pressure with increase in well inclination.

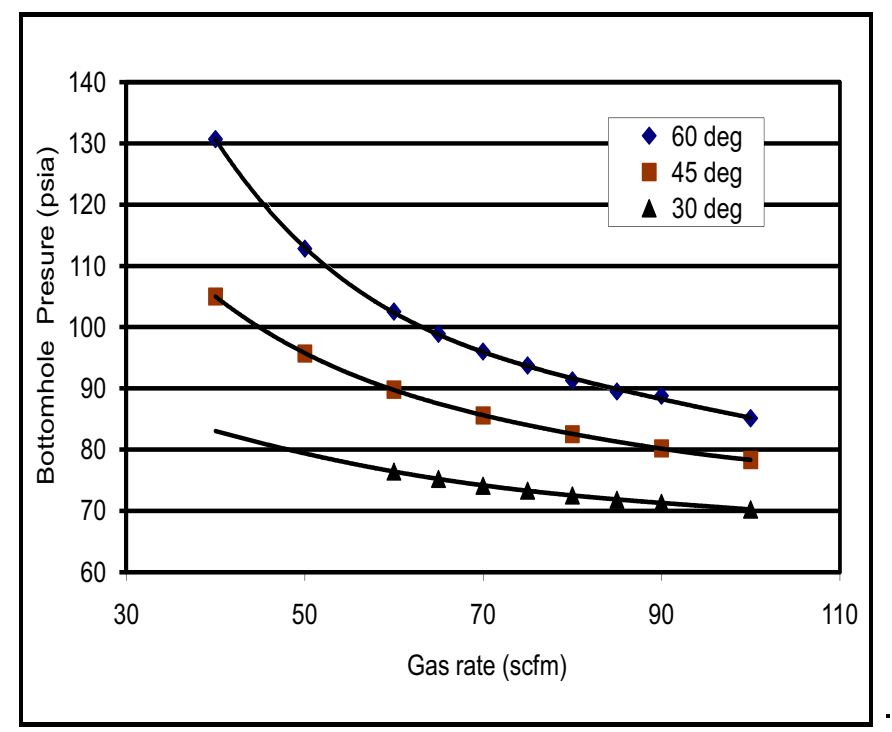

Fig. (7). Bottomhole pressure variation with inclination.

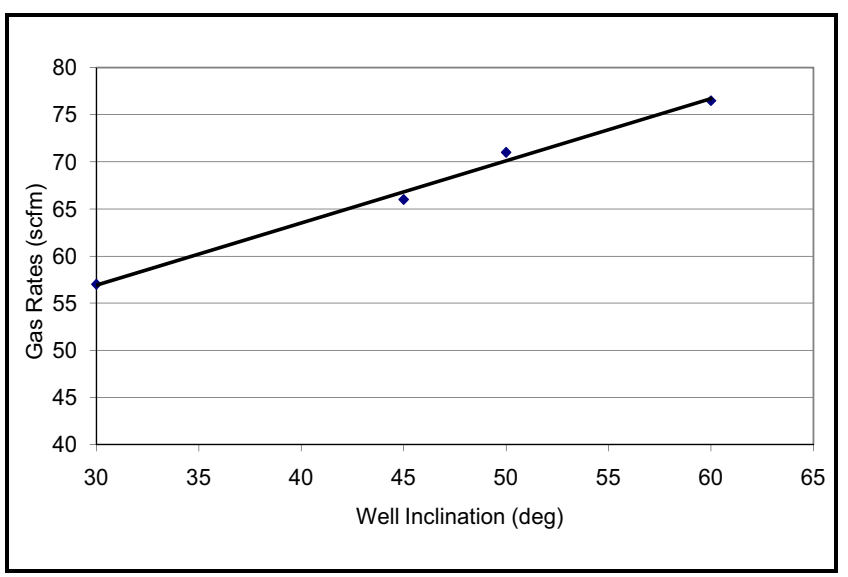

Fig. (8). Gas injection rate variation with well inclination.

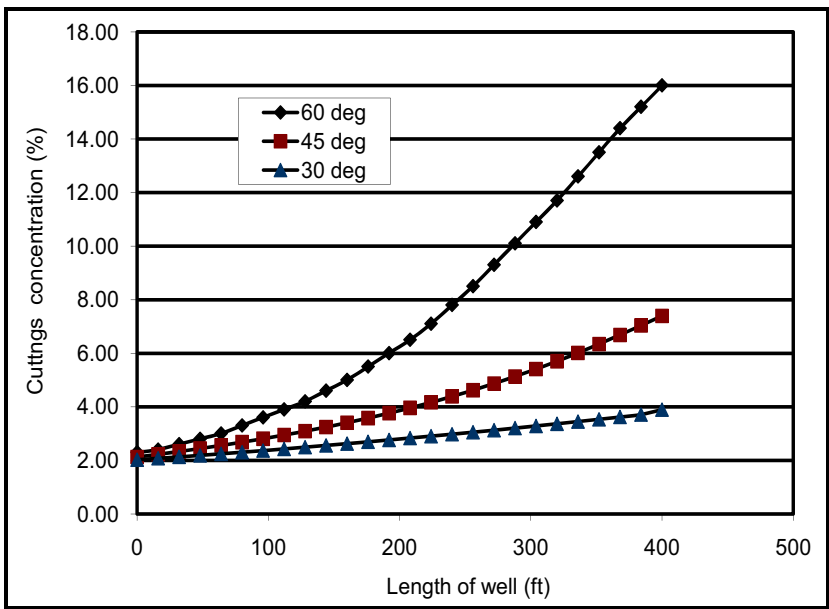

Fig. (9). Cuttings concentration profile variation with inclination.

Also shown by Fig. (9) is the increase in the cuttings concentration at a particular sectional length of the wellbore with increase in the inclination angle. The effect of inclination on both bottomhole pressure and average cutting concentration in the annulus is more pronounced at lower gas injection rates.

\section{Effect of Water Influx on Bottomhole Pressures and Cut- tings Concentrations}

Increase in water influx increases the cuttings concentration along the wellbore for a fixed gas and liquid injection rate as depicted by Fig. (10).

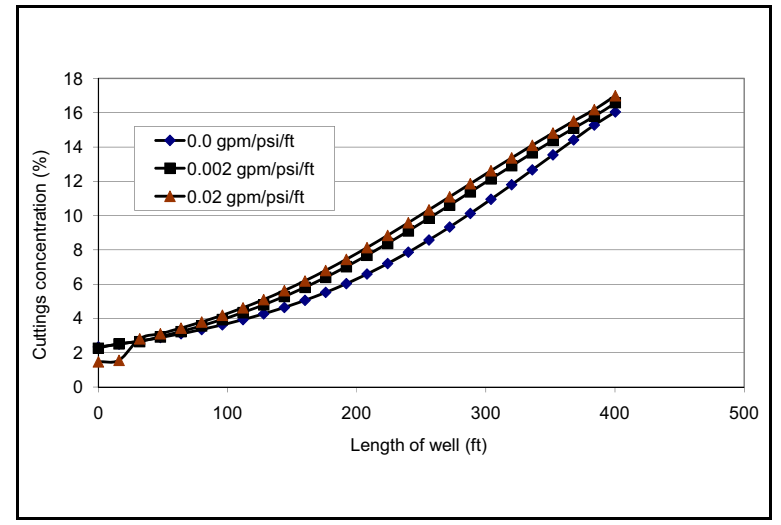

Fig. (10). Cuttings concentration profile variation with water influx from reservoir. 
This foam quality is reduced due to water influx from formation into the wellbore, which in turns reduces the effective viscosity of foam and therefore lifting capacity of the foam is decreased. Fig. (11) shows the effect water influx on the pressure across the length of the wellbore at steady flow condition.

Results indicate that an increase in water influx from the reservoir increases pressure along the wellbore. This increase in pressure along the well is attributed to increase in the foam density due to water influx from the reservoir and the increase in the cuttings concentration associated with the influx.

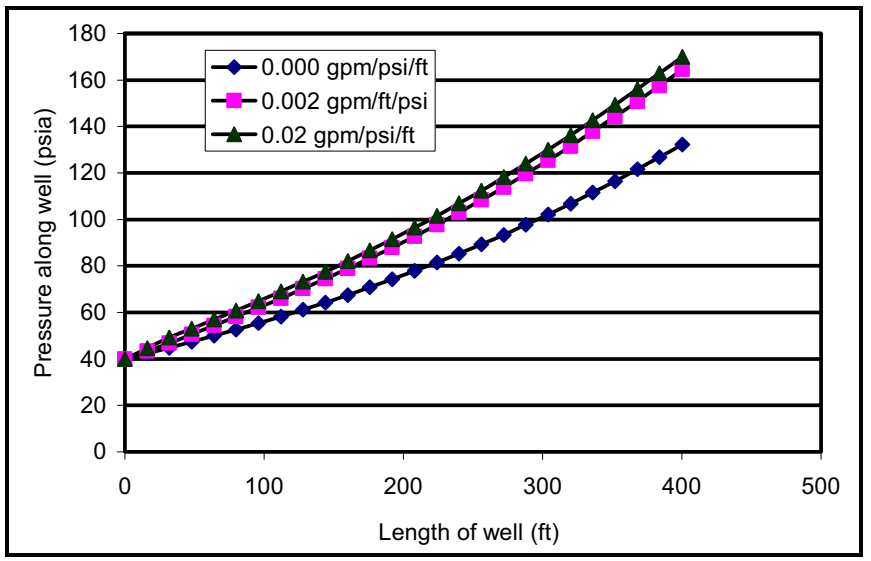

Fig. (11). Pressure profile variation with water influx from reservoir.

\section{Effect of Gas Influx on Bottomhole Pressure and Cut- tings Concentration}

Figs. $(12,13)$ illustrate the effect of reservoir gas influx on the cuttings concentration and pressure profile along the length of the well respectively. The influx of gas into the wellbore has a positive effect on the cuttings transport process reducing cuttings concentration as shown in Fig. (12).

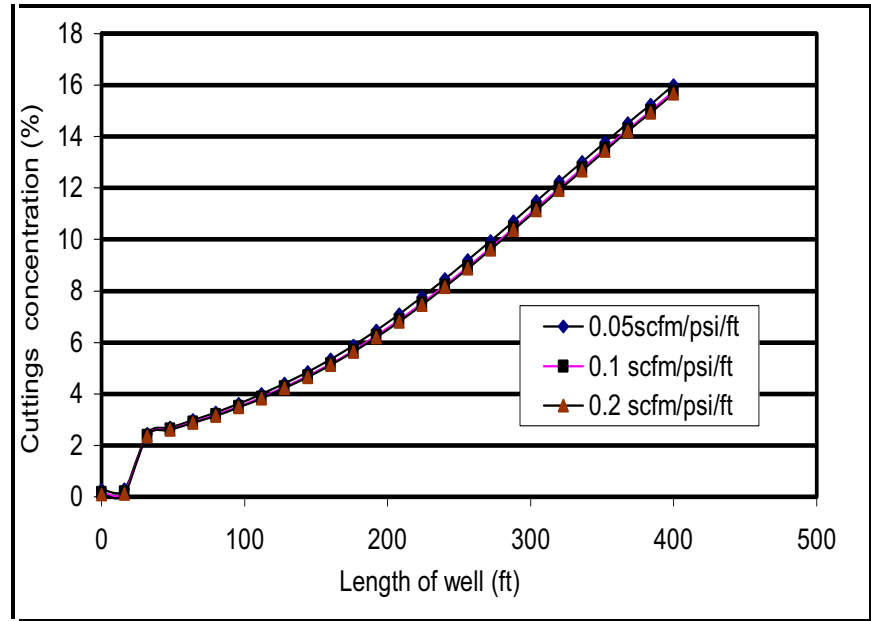

Fig. (12). Cutting concentration variation with gas influx from the reservoir.

The influx of gas increases the effective viscosity of foam, which enhances the cuttings lifting and transport ability of foam. From Fig. (13), it is seen that increase in gas influx reduces bottomhole pressure. This is because the in- flux of gas into the wellbore increases the foam quality which in turns reduces the density of foam. The decrease in the cuttings concentration resulting from increase in the gas influx reduces the bottomhole pressure.

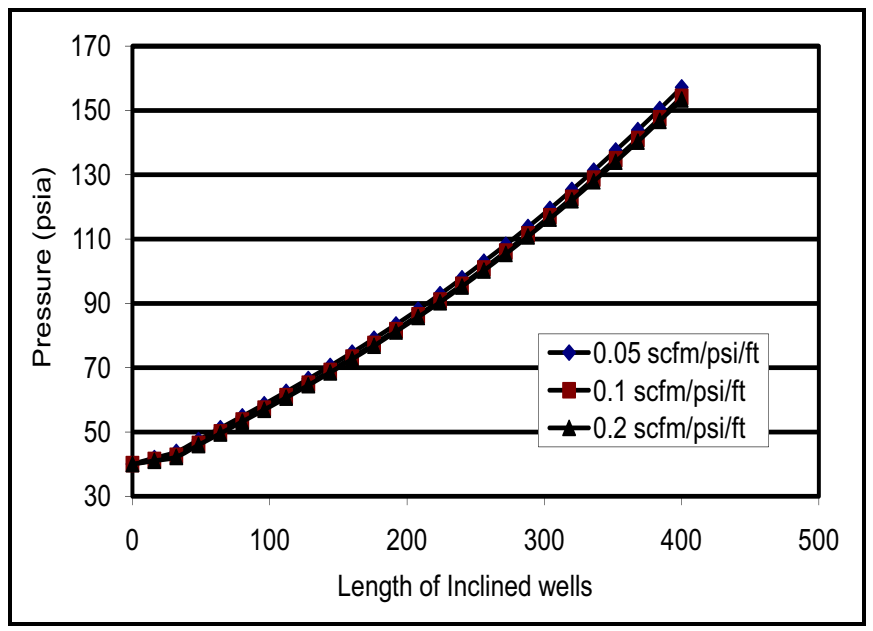

Fig. (13). Pressure profile variation with gas influx from reservoir.

\section{Transient Bottom Hole Pressure and Cuttings Concen- tration}

Fig. (14) shows changes in bottomhole pressure with time as drilling progresses for different drilling rate at 60 degree inclination. Results indicate that the higher the drilling rate, the longer the drilling time require for stabilization of the bottomhole pressure.

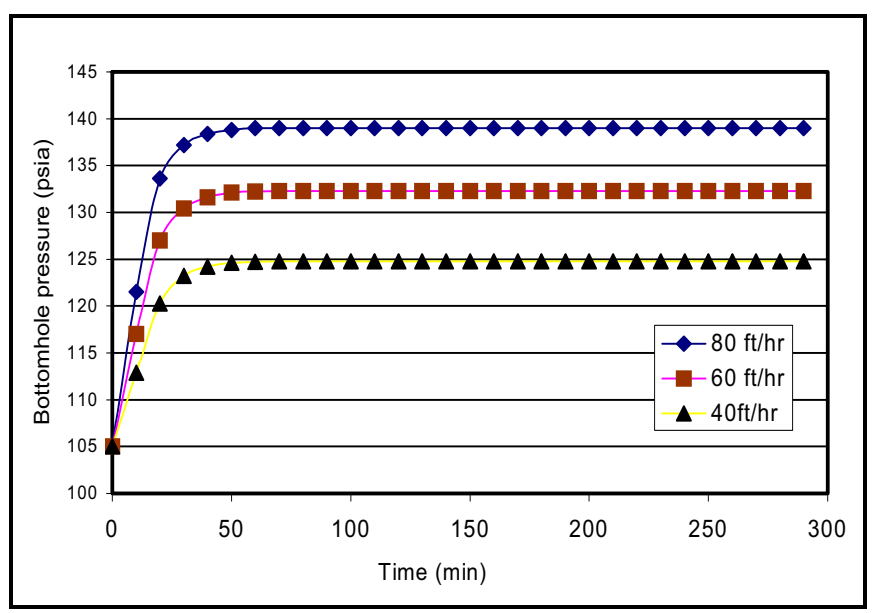

Fig. (14). Transient bottomhole pressure at different drilling rate.

Fig. (15) illustrates the changes in the average cuttings concentration in the annulus with time. The trend in Fig. (15) is very similar to that in Fig. (14). This similarity in trend indicates that change in the bottomhole pressure as a function of time is directly proportional to change in the average cuttings concentration as a function of time irrespective of the inclination angle.

Figs. $(\mathbf{1 6}, \mathbf{1 7})$ further illustrate variation of cutting concentration and bottomhole pressures with time for different inclination angles. For a fixed drilling rate, the time required for the cuttings concentration to stabilize increases with the increasing inclination angle (Fig. 16). The change in bottom hole pressure is directly related to the change in average cut- 
tings concentration irrespective of the inclination of the well. Therefore, the time required for bottomhole pressure to stabilize also increases with increasing inclination angle (Fig. 17).

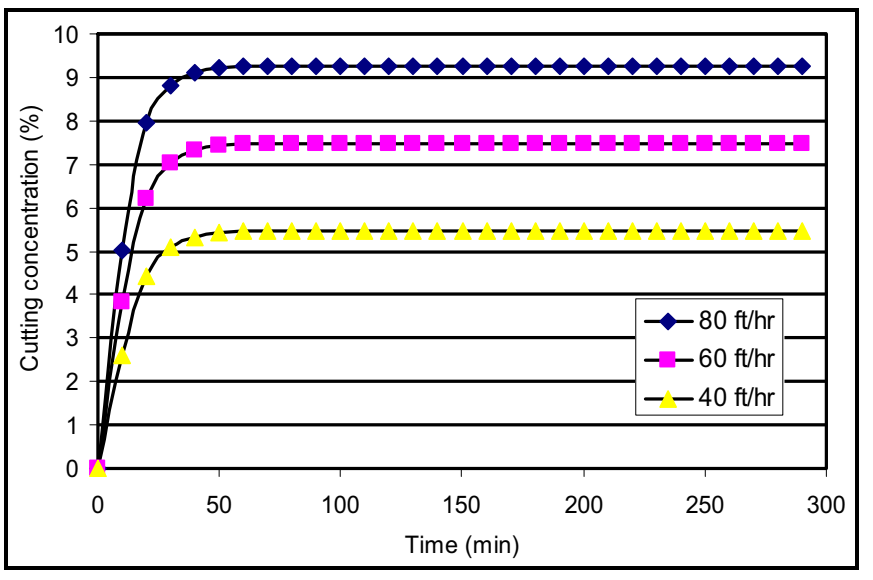

Fig. (15). Transient average cuttings concentration at different drilling rate.

Fig. (18) illustrates the distribution of cuttings along the well at different times for a fixed drilling rate. Results indicate that cuttings are not uniformly distributed even after stabilization (in this figure, steady state flow was achieved after about 50 minutes) and that maximum cuttings concentration occurs at the bottom of the hole.

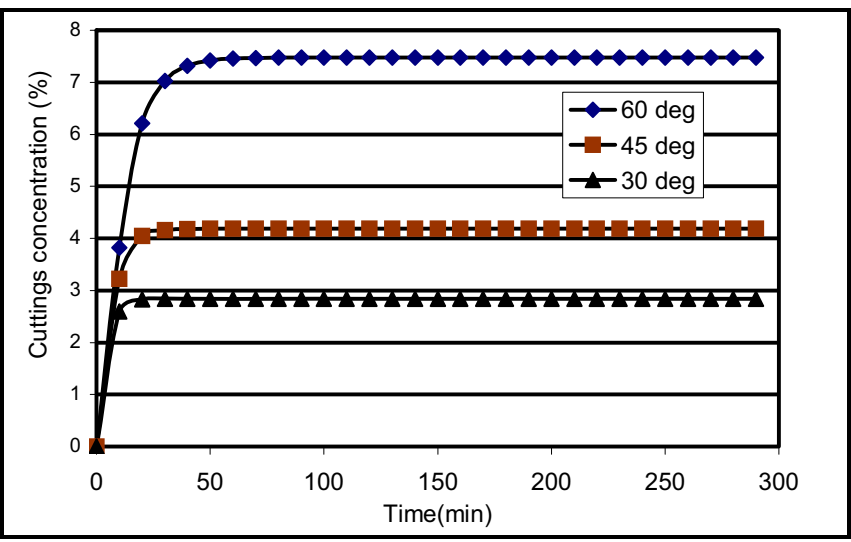

Fig. (16). Transient average cuttings concentration at different inclination.

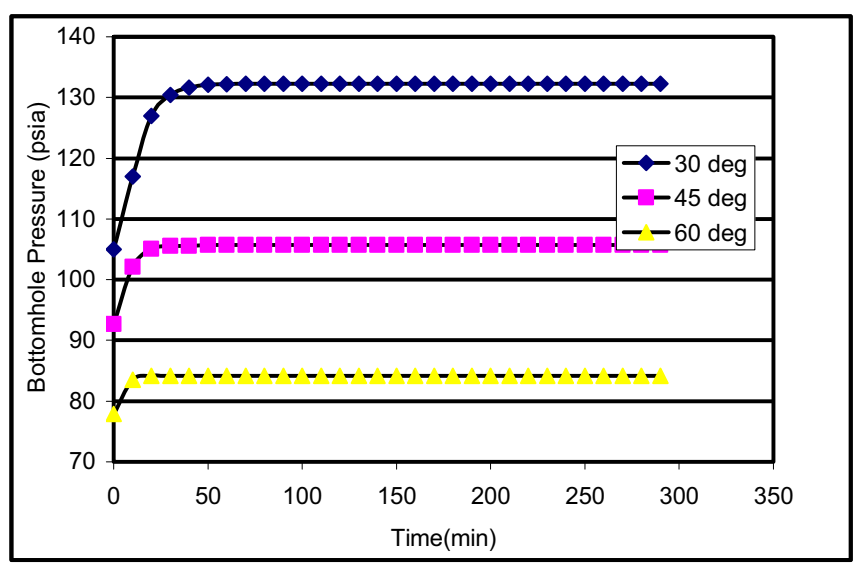

Fig. (17). Transient bottomhole pressure at different inclination.

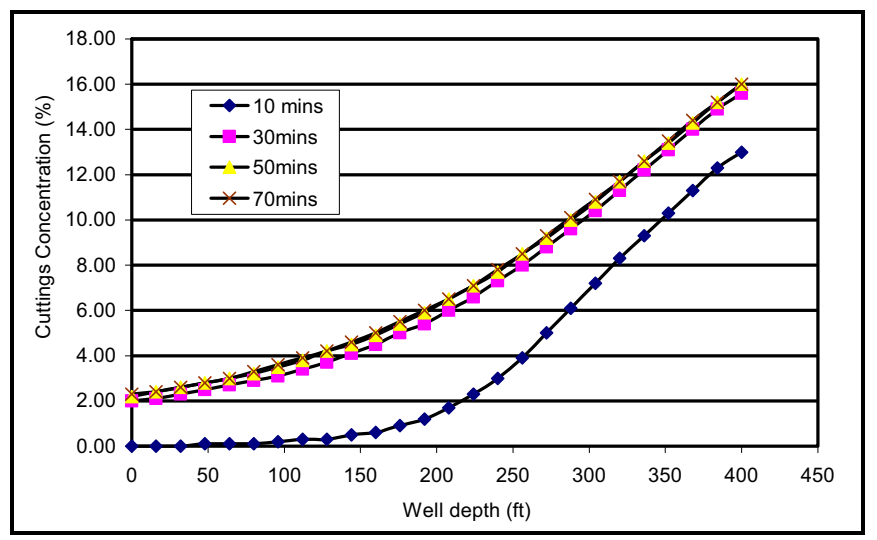

Fig. (18). Cuttings concentration profile along wellbore.

\section{CONCLUSIONS}

A 1-D transient state mechanistic model of cuttings transport with foam in inclined wells has been developed. The model is solved numerically to predict the optimum foam flow rate (liquid and gas rate) and rheological properties that would maximize cuttings transport efficiency in inclined well.

The model developed in this paper was verified using experimental results obtained by Capo [73]. The new model predictions were lower than the measured pressure values by about 4 to $21 \%$.

The gas injection rate has a significant effect on the cuttings transport process, with effect more pronounced at lower gas injection rates. The liquid injection rate has little effect on the cuttings transport process with negligible effect at very low or very high gas injection rate.

The well inclination is a major factor in cuttings transport in inclined wells. The cuttings transport efficiency decreases with increase in well inclination from the vertical under the same flow condition.

The influx of gas into the wellbore enhances the cutting transport efficiency whereas water influx reduces the cuttings transport efficiency. The effect of gas influx is more pronounced at the low gas injection rate region because of the increase in foam quality. The effect of water influx is more significant at high gas injection rates where it causes a reduction in the quality of the foam.

The concentration of cuttings in the wellbore increases with drilling rate. The average concentration of cuttings in the annulus and the bottomhole pressure does not stabilize as soon as the drilling begins. The time required for achieving stabilized bottomhole pressure increases with increasing drilling rate and with increasing inclination of the well from the vertical position.

Even when the steady state flow condition is achieved, the distribution of cuttings along the annulus is not uniform. The highest concentration of the cuttings is always at the bottom of the hole and the lowest is at the top.

\section{ACKNOWLEDGEMENT}

This work is supported through the research grant provided by the Natural Sciences and Engineering Research Council (NSERC) of Canada. 


\section{DEDICATION}

This paper is dedicated to the memory of Osunde Okunsebor Macdonald who passed away shortly after completing his MSc degree at the University of Alberta. Research results presented in this paper were obtained by Osunde Okunsebor Macdonald during his MSc thesis study.

\section{NOMENCLATURE}

$$
\begin{array}{ll}
\mathrm{A} & =\text { Cross-sectional area, } \mathrm{ft}^{2} \\
\mathrm{C} & =\text { Volumetric concentration, dimensionless } \\
\mathrm{C}_{\mathrm{f} 1} & =\text { Foam concentration in lower layer, } \\
& =\text { dimensionless } \\
\mathrm{C}_{\mathrm{s} 1} & =\text { Solid concentration in lower layer, } \\
& \text { dimensionless } \\
\mathrm{CBHP} & =\text { Circulating bottom hole pressure (psia) } \\
\mathrm{D}_{\mathrm{H}} & =\text { Hydraulic diameter, } \mathrm{ft} \\
\mathrm{f} & =\text { Friction factor } \\
\mathrm{g} & =\text { Acceleration of gravity, } \mathrm{ft} / \mathrm{sec}^{2} \\
\mathrm{~g}_{\mathrm{c}} & =\text { Newton's law conversion factor, } \mathrm{ft}-\mathrm{lbm} / \mathrm{lbf}- \\
\mathrm{sec}^{2} & \\
\mathrm{~K} & =\text { Consistency index, Ibf-sec }{ }^{\mathrm{n}} / \mathrm{ft}^{2} \\
\dot{m} & =\text { Mass flow rate, } \mathrm{Ibm} / \mathrm{sec}^{2} \\
\mathrm{n} & =\text { Flow behavior index }
\end{array}
$$

$\mathrm{N}_{\mathrm{Re}}(\mathrm{n}, \bar{k})=$ Modified Reynolds number for laminar flow in annulus, dimensionless

$\mathrm{p} \quad=$ pressure in wellbore, $\mathrm{psia}$

PI $\quad=$ Specific productivity index, $\mathrm{ft}^{2} /($ psi.sec $)$

$\Delta \mathrm{P}_{\mathrm{d}} \quad=$ Parasitic pressure loss, psia

$\Delta \mathrm{P}_{\mathrm{b}} \quad=$ Pressure drop across the bit, psia

$\mathrm{q}=$ Flow rate, $\mathrm{ft}^{3} / \mathrm{sec}$

$\mathrm{Q} \quad=$ Flow rate, $\mathrm{ft}^{3} / \mathrm{sec}$

$\operatorname{Re} \quad=$ Reynolds number, dimensionless

ROP $=$ Rate of Penetration, $\mathrm{ft} / \mathrm{hr}$

$\mathrm{s}_{\mathrm{f}} \quad=$ Source term of foam, $\mathrm{lbm} /\left(\mathrm{sec} \cdot \mathrm{ft}^{3}\right)$

$\mathrm{S} \quad=$ length, $\mathrm{ft}$

$\Delta \mathrm{S} \quad=$ Length of control volume, $\mathrm{ft}$

$\mathrm{u} \quad=$ Velocity, $\mathrm{ft} / \mathrm{sec}$

$\mathrm{u}_{\mathrm{t}}=$ terminal settling velocity of solids, $\mathrm{ft} / \mathrm{sec}$

$\mathrm{V} \quad=$ Volume, $\mathrm{ft}^{3}$

$\mathrm{V}_{\mathrm{D}} \quad=$ Depositional velocity, $\mathrm{ft} / \mathrm{sec}$.

$\mathrm{V}_{\mathrm{E}} \quad=$ Entrainment velocity, $\mathrm{ft} / \mathrm{sec}$.

$\mathrm{Z}=$ Compressibility factor

$\beta_{\mathrm{v}} \quad=$ Coefficient accounting for drag force, $\mathrm{lbm} /\left(\mathrm{sec} \cdot \mathrm{ft}^{3}\right)$

$\theta=$ Well inclination from the vertical, degree
$=$ Cutting angle of repose, degree

$\Gamma=$ Foam quality, dimensionless

$\rho=$ Density, $1 \mathrm{bm} / \mathrm{ft}^{3}$

\section{Subscripts}

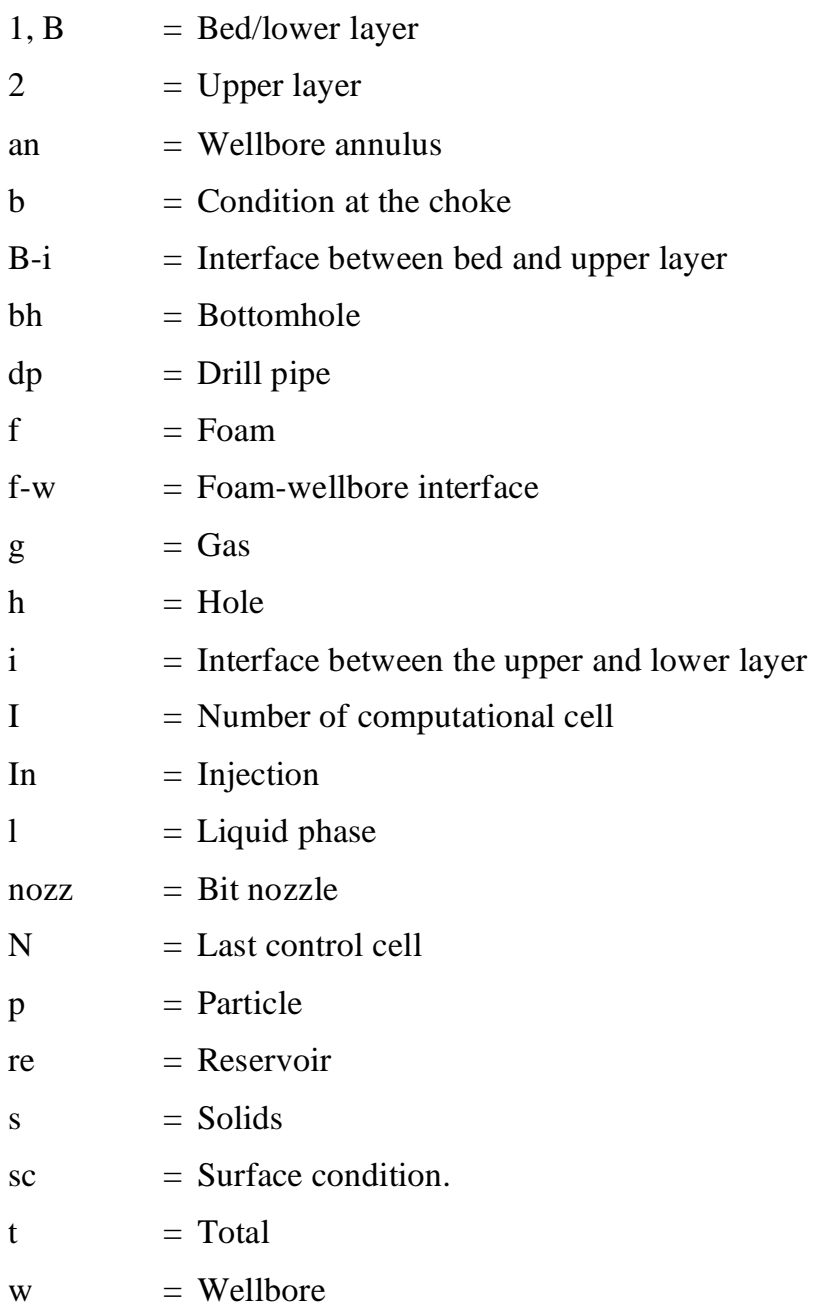

\section{APPENDIX - A: OTHER CLOSURE EQUATIONS}

\section{Foam Quality and Density (Equation of State)}

In this study, foam is considered as a dispersion of gas in liquid in which gas forms a large portion of the mixture. The foam quality $(\Gamma)$ has a value ranging from 0 to 1 depending on the amount of gas in the foam. The expression for the foam quality is given by:

$$
\Gamma=\frac{V_{g}}{V_{g}+V_{L}}
$$

The presence of gas component in foam makes it quality to change with temperature and pressure. The real gas law can be used to determine the gas volume ratio at different temperature and pressure. With the volume of gas in the foam at condition 1 known, the volume of gas in the foam at another condition of temperature and pressure can be obtained using; 
$V_{g 2}=V_{g 1}\left(\frac{Z_{2} P_{1} T_{2}}{Z_{1} P_{2} T_{1}}\right)$

The volume of foam at another condition of temperature and pressure can be obtained using;

$V_{2}=V_{1}\left(\left(1-\Gamma_{1}\right)+\frac{Z_{2} P_{1} T_{2}}{Z_{1} P_{2} T_{1}} \Gamma_{1}\right)$

The gas density at the new condition can be obtained by using:

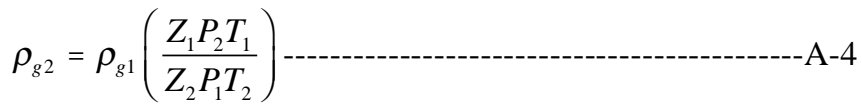

The foam quality at the new condition can be calculated by combining equation (A-1) and (A-2) to obtain:

$\Gamma_{2}=\left(1+\left(\frac{1-\Gamma_{1}}{\Gamma_{1}}\right)\left(\frac{Z_{1} P_{2} T_{1}}{Z_{2} P_{1} T_{2}}\right)\right)^{-1}$

The Z-factor (gas deviation factor) in the equations above is obtained using Yarborough and Hall method [74].

\section{Foam Density}

The change in the volume of the gas phase of foam with change in temperature and pressure will cause the density of the foam to change. For foam flow, it is assumed that the liquid volume does not change with temperature and pressure i.e. the volume of the liquid phase is constant. For a particular pressure and temperature condition, foam is treated as a homogenous fluid and the density can be calculated by using:

$\rho_{f}=\Gamma \rho_{g}+(1-\Gamma) \rho_{L}$ A-6

To obtain the density of foam at different temperature and pressure, equations (A-3), (A-4) and (A-5) are combined:

$\rho_{f 2}=\frac{\rho_{f 1} Z_{1} P_{2} T_{1}}{Z_{1} P_{2} T_{1}\left(1-\Gamma_{1}\right)+Z_{2} P_{1} T_{2} \Gamma_{1}}$

\section{Foam Rheology}

Studies have shown that foams can be treated as pseudoplastic (power law) fluids [75-79], as Bingham plastic fluids [80-82] and even as yield-pseudoplastic fluids [83-84]. Ozbayoglu et al. [85] carried out a comparative study of the foam hydraulic models. They suggested that foams can be modeled as a power law fluid when the foam quality is 70$80 \%$ and as a Bingham plastic fluid when the foam quality is $90 \%$.

In this study, foam is characterized by the power law model. A generalized power law rheological behavior is defined by Equation (A-8).

$$
\tau=K\left(\frac{d u}{d r}\right)^{n}
$$

\section{Foam Viscosity}

Li [66] based on Sanghani and Ikoku [78] experimental results developed correlations for the determination of $n$ and $\mathrm{K}$ through regression analysis. He found that two different correlations exist for two different range of foam quality. When the foam quality is less or equal to $0.915, \mathrm{n}$ and $\mathrm{K}$ are linear function of the quality but above a quality of 0.915 , exponential relationship exists between $\mathrm{n}$ and $\mathrm{k}$ and foam quality. The equations developed by $\mathrm{Li}$ [66] are as follows:

For $\Gamma \leq 0.915$

$$
\begin{aligned}
& K=0.0074 e^{3.5163 . \Gamma} \\
& n=1.2085 e^{-1.9897 \Gamma}
\end{aligned}
$$

For $0.98>\Gamma>0.915$

$$
\begin{aligned}
& K=-2.1474 \Gamma+2.1569 \\
& n=2.5742 \Gamma-2.1649
\end{aligned}
$$

These correlations developed by $\mathrm{Li}[66]$ were used in this study.

\section{Drag Coefficient for Foam}

The drag coefficient $C_{D}$ in equations (7) and (8) is required for the calculation of the drag force. The determination of this coefficient for Newtonian fluids has been a subject of numerous investigations in the past [86-88]. Several drag coefficient models for non-Newtonian fluids have also been proposed [89-95]. Chhabra [96] carried out a detailed comparison of the different correlations developed by the different authors for power law fluids and found out that correlations by Acharya et al. [93] and Matijasic and Glasnovic [95] gave the best result followed by that of Darby [94]. For the model developed in this paper, the following expressions for drag coefficient were used.

$$
C_{D}=\left(\frac{24}{\operatorname{Re}}\right)(-1.26 n+2.3)+0.653 \text {--------------A-13 }
$$

$0.01<\mathrm{Re}_{\mathrm{p}}<700$

$C_{D}=\frac{24 X(n)}{\operatorname{Re}_{p}}+\frac{F_{1}}{\operatorname{Re}_{p}^{F_{2}}}$

$700 \leq \operatorname{Re}_{\mathrm{p}}<1000$

where $X=3^{1.5(1-n)}\left(\frac{2-22 n^{2}+29 n}{n(n+2)(2 n+1)}\right) \begin{aligned} & F_{1}=10.5 n-3.5 \\ & F_{2}=0.32 n+0.13\end{aligned}$

$C_{D}=\frac{30.0}{\operatorname{Re}_{p}}+\frac{67.289}{e^{5.03}}$

$\operatorname{Re}_{\mathrm{p}} \geq 1000$

For all the cases above, the particle Reynolds's number is obtained by using the expression,

$$
\operatorname{Re}_{p}=\frac{8^{1-n} \rho_{f}\left|u_{f}-u_{s}\right|^{2-n} d_{s}^{n}}{K_{f}\left(\frac{(3 n+1)}{4 n}\right)^{n}}
$$


Equations (A-13), (A-14) and (A-15) are the Matijasic and Glasnovic [95], Acharya et al. [93] and Chien models [97], respectively for the determination of drag coefficient for power law fluid.

\section{Friction Factor}

The terms $f_{s,} f_{f}$ and $f_{1}$ in equations (7), (8) and (9) are the solid, foam and cuttings bed frictional force respectively. Different empirical correlations have been developed for the determination of the solid friction factor [98-101]. In this paper, the correlation developed by Cape and Nakamura [99] (equation (A-17)) which gave the highest solid frictional pressure drop was used.

$$
f_{s}=\frac{0.206}{u_{s}^{1.22}}
$$

The friction factor for the flow of power law fluid through pipes and the annulus depends on the flow regime. For turbulent flow of power law fluid through pipes and annulus, the Dodge and Metzner expression for fanning friction factor is used [102].

$$
\sqrt{\frac{1}{f_{f}}}=\frac{4.0}{n^{0.75}} \log \left(\operatorname{Re}_{f} \cdot f_{f}^{1-n / 2}\right)-\frac{0.395}{n^{1.2}}
$$

where $\mathrm{Re}_{\mathrm{f}}$ is the generalized Reynolds number for power law fluid modified for foam calculated using equation (A-19).

$$
\operatorname{Re}_{f}=\frac{8^{1-n} \rho_{f} u_{f}^{2-n} d^{n}}{K_{f}\left(\frac{(3 n+1)}{4 n}\right)^{n}}
$$

For laminar flow of power law fluid through the pipe, the fanning friction factor is obtained using

$$
f_{f}=\frac{\alpha_{s}}{\left(\operatorname{Re}_{f}\right)^{\beta_{s}}}
$$

where $\alpha_{s}=16$ and $\beta_{s}=1$.

Frederickson and Bird [103-104] have shown that the friction factor for the laminar flow of power law fluids in annuli could be written as follows:

$$
f_{f}=\frac{16}{N_{\mathrm{Re}}(n, \bar{\kappa})}
$$

In which the modified Reynolds number $N_{\mathrm{Re}}(n, \bar{\kappa})$ is defined as:

$$
N_{\mathrm{Re}}(n, \bar{\kappa})=\frac{\left(2 R_{2}\right)^{n} u^{2-n} \rho / K}{2^{n-3}\left(1-\bar{\kappa}^{2}\right)^{n+1} /(1+\bar{\kappa})} \Omega_{p}^{n}
$$

$$
\bar{\kappa}=R_{1} / R_{2}
$$

$\Omega_{p}=\frac{n \Psi(1-\bar{\kappa})^{(2 n+1) / n}}{2 n+1}$

Values of $\Psi$ was tabulated as a function of $n$ and $\bar{\kappa}$ in Table-III of reference 103. For convenience, values given in Table-III were curve fitted and could be represented by the following two parametric equations:

When $0.3<\bar{\kappa} \leq 1.0$

$\Psi(\mathrm{s}, \bar{\kappa})=\left(0.0011 \mathrm{~s}^{2}-0.0217 \mathrm{~s}+0.4972\right) \bar{\kappa}-0.0009 \mathrm{~s}^{2}+$ $0.0178 \mathrm{~s}+0.5023$---

When $\bar{\kappa} \leq 0.3$

$\Psi(\mathrm{s}, \bar{\kappa})=\left(0.0715 \mathrm{~s}^{2}+1.0241 \mathrm{~s}+0.4402\right) \bar{\kappa}^{2}+\left(0.0361 \mathrm{~s}^{2}-\right.$ $0.5412 \mathrm{~s}+0.2972) \bar{\kappa}-0.0052 \mathrm{~s}^{2}+0.0851 \mathrm{~s}+0.5237 \quad-\mathrm{A}-26$

where $\mathrm{s}=1 / \mathrm{n}$

Note that the values of the function $\Psi(\mathrm{s}, \bar{\kappa})$ can be calculated by using equations (A-25) and (A-26) within less than 3\% error margin of Frederickson and Bird solution [104].

For the turbulent flow of power law fluid through the annulus, the Reynolds number used for the calculation of the friction factor is the same as that used for turbulent flow of power law fluid through pipes.

The friction factor for the moving cuttings bed is calculated by using equations (A-27) to (A-29)

$$
\begin{aligned}
& f_{B-w}=\frac{16}{\left(\operatorname{Re}_{B}\right)} \\
& \operatorname{Re}_{B}=\frac{\rho_{B} u_{B}^{2-n} d_{1}^{n}}{8^{n-1} K_{B}^{\prime}} \\
& K_{B}^{\prime}=K_{f}^{\prime}\left(1+2.5 C_{s 1}+10.05 C_{s 1}^{2}+0.00273 e^{16.6 C_{s 1}}\right)----\mathrm{A}-29
\end{aligned}
$$

\section{Friction Force between Cuttings Bed and Wellbore}

The symbol $F_{1}$ in equation (9) is the frictional force which results due to contact of the cuttings bed with the wall of the wellbore. For stationary bed, the static frictional force on the bed balances the driving forces acting on it. Increasing the driving force on the bed would increase the dry frictional force until it reaches a certain maximum value. At this point, a further increase in the drive force will cause the bed to slide. This maximum frictional force acting at the point of sliding is given by:

$F_{1}=\mu R$ A-30

where 
where $\mu$ is the dry friction coefficient and $\mathrm{R}$ is the sum of normal forces exerted by the solid particles on the wall of the pipe. The normal force " $\mathrm{R}$ " is composed of two components:

1. The first component $\left(\mathrm{R}_{1}\right)$ is that due to the submerged weight of the solid particle. $R_{1}$ is calculated using the equation (A-31).

$$
R_{1}=\rho_{1} A_{1} g \Delta s
$$

2. The second component is due to the transmission of stress from the interface through the cuttings in the bed. This component represented by $\mathrm{R}_{2}$ is sometimes referred to as the Bagnold stresses. Bagnold [105106] showed that when fluid flows over a moving bed, a normal stress exist at the interface which is associated with the shear stress exerted by the fluid on the bed. The Bagnold stress for a cutting bed is calculated using equation (A-32).

$$
R_{2}=\frac{\tau_{i} S_{i}}{\tan \phi} \Delta s
$$

Combining equations (A-30), (A-31) and (A-32) gives:

$$
F_{1}=\mu\left(\rho_{1} A_{1} g \operatorname{Sin} \theta+\frac{\tau_{i} S_{i}}{\tan \phi}\right) \Delta s
$$

where $\phi$ is angle of internal friction with value of $\tan \phi$ ranging from 0.35 to 0.75 depending on the type of flow and the particle characteristics; $\mu$ is the dry coefficient of friction when a moving bed is considered.

Tomren et al. [30] indicated that the coefficient of static friction is about 0.6 , since cuttings slide down the wellbore under no flow condition when the wellbore makes an angle of about $60^{\circ}$ with the horizontal. A close approximation for the value of the coefficient of static friction is the tangent of the angle the wellbore makes with the horizontal at which the cutting bed will just begin to slide under no flow condition. This is approximately equal to the tangent of the cuttings angle of repose.

Gavignet and Sobey [53] showed that for a sliding bed, the sliding coefficient of friction is less than half the coefficient of static friction of the cuttings studied by Tomren et $a l$. [30]. Gavignet and Sobey [53] suggested a sliding friction factor of 0.2. Ozbayoglu [60] also presented empirical correlation for the determination of this coefficient expressed as a function of $A_{b e d} / A_{w}$ given by:

$\mu=0.617\left(\frac{A_{b e d}}{A_{w}}\right)^{0.252}$

For stationary beds, equation (A-34) cannot be used to directly calculate the static dry friction force as this applies to a bed at the verge of motion. The static dry frictional force for a stationary bed is calculated from the momentum equation for the bed. The friction force calculated should be less than maximum dry friction obtained using equation (A-34) (Wilson [107]). A stationary bed would be at the verge of moving if the calculated frictional force from the momentum equation is equal to that obtained from equation (A-34).

\section{Re-suspension and Deposition Velocity}

The velocities $V_{E}$ and $V_{D}$ in equations (1) to (3) and (7) to (9) are the entrainment and depositional velocity due to resuspension and deposition of materials from one layer to the other. The re-suspension process has been investigated by many researchers. Gadala-Maria [108] was the first to show re-suspension can occur at small values of Reynolds number for which inertia effects are insignificant and flow is laminar. Leighton and Acrivos [109] also investigated the resuspension process and explain it in terms of shear-induced diffusion process, in which the diffusivity resulted from inter-particle interaction within a suspension as it is sheared.

Doan et al. [62] assumed that deposition and entrainment rates determine the volumetric transfer rate across the interfacial boundary aligned in the direction perpendicular to bulk flow. The depositional rate was expressed as a function of hindered terminal velocity of a single particle. The force

balance on a single particle was used to determine an expression needed for the determination of the hindered terminal velocity in inclined wells. They did not consider the inclination effect in the determination of force associated with this process which, however, was included in the model described in this paper.

Doron et al. [68] suggested the use of the following equations for the determination of depositional rate. The equation takes into consideration the concentration effects on the hindered terminal velocity.

$v_{D}=v_{p}\left(1-C_{s}\right)^{m}$ A-35

$v_{p}$ is the terminal settling velocity obtained by using:

$$
\begin{aligned}
& v_{p}=\sqrt{\frac{4 d_{p} g}{3 C_{D}}\left(\frac{\rho_{s}-\rho_{f}}{\rho_{f}}\right)} \\
& m=4.45 \operatorname{Re}_{p}-0.1 \mathrm{RE}_{\mathrm{p}}<500 \\
& m=2.39 \quad \quad \mathrm{RE}_{\mathrm{p}} \geq 500
\end{aligned}
$$

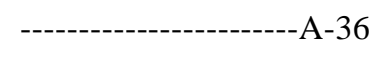

$\mathrm{RE}_{\mathrm{p}}$ is the Reynolds number based on $v_{D}$ the hindered terminal velocity depositional rate.

$$
\operatorname{Re}_{p}=\frac{8^{1-n} \rho_{f}\left(v_{D}\right)^{2-n} d_{s}^{n}}{K_{f}\left(\frac{(3 n+1)}{4 n}\right)^{n}}
$$

Doron et al. [68] expressed the entrainment rate as a function of the interfacial shear velocity. They calculated the interfacial shear velocity using equation (A-40). 
$u_{12}=\sqrt{\frac{\tau_{12}}{\rho_{f}}}=\sqrt{\frac{\frac{1}{2} f_{i} \rho_{f}\left(u_{2}-u_{1}\right)^{2}}{\rho_{f}}}=\left(u_{2}-u_{1}\right) \sqrt{\frac{f_{i}}{2}}$------------A-40

Doan et al. [62] assumed a linear relationship between the entrainment velocity and the difference between the interfacial velocity $\left(u_{12}\right)$ and a critical threshold velocity $\left(u_{12}^{*}\right.$ ), given by equation (A-41). The slope $m^{\prime \prime}$ was obtained from simulation study.

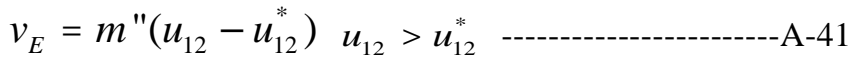

$$
\begin{aligned}
& v_{E .}=\mathrm{O} \quad u_{12} \leq u_{12}^{*}
\end{aligned}
$$

When the interfacial shear velocity is below a certain critical level as shown by equation (A-42) there would be no re-entrainment of deposited cuttings into the flowing suspension layer.

\section{Foam-Cutting flow in Drilling Annulus}

The numerical solutions of equations (1) to (3) and (7) to (9) which describe the cuttings transport mechanism in the annulus are needed in order to determine the flowing bottomhole pressure and the cuttings concentration along the well. For foam-cuttings transport under steady state flow condition, the total pressure drop across the annulus can be calculated by using the equation (A-43).

$$
\begin{aligned}
& \Delta P_{a n}=\Delta s \sum_{i}\left(C_{s} \rho_{s}+C_{f} \rho_{f}\right) g \operatorname{Cos} \theta+ \\
& \Delta s \sum_{i}\left(\begin{array}{l}
\frac{1}{2} C_{f} f_{f} \rho_{f} u_{f}^{2} \frac{S_{2}}{A_{2}}+\frac{1}{2} C_{s} f_{s} \rho_{s} u_{s}^{2} \frac{S_{2}}{A_{2}}+ \\
\frac{1}{2} C_{f} f_{f} \rho_{f}\left(u_{f}-u_{1}\right)^{2} \frac{S_{i}}{A_{2}} \\
+\frac{1}{2} C_{s} f_{s} \rho_{s}\left(u_{s}-u_{1}\right)^{2} \frac{S_{i}}{A_{2}}
\end{array}\right)
\end{aligned}
$$

The total pressure drop across the annulus as shown by the equation (A-43) can be obtained by dividing the annulus into sections and summing up the pressure drops in all the sections. The circulating bottom-hole pressure is the sum of the total pressure drop across the annulus and the back pressure applied at the surface.

$$
C B H P=\Delta P_{a n}+P_{b}
$$

\section{Foam Flow Across the Bit Nozzle}

The determination of the pressure drop across the bit needs modification of the momentum equation for the suspended foam. Due to the fact that high pressure foam flows through the bit nozzles, the frictional, gravitational and mass transfer terms can be neglected in comparison to the acceleration term in equation (8).

$\frac{\partial\left(C_{f} \rho_{f} u_{f}^{2}\right)}{\partial s}=-C_{f} \frac{\partial p}{\partial s}$ A-45

The finite difference equation for foam flow through the bit nozzle is given by equation (A-46).

$$
P_{d p, N}=P_{a n, 1}+\left(\rho_{f} u_{f_{f}}^{2}\right)_{n o z z}-\left(\rho_{f} u_{f_{f}}^{2}\right)_{d P, N}
$$

\section{Foam Flow in Drill Pipes}

The flow of foam in a drill pipe is considered a steady state flow of single-phase compressible fluid in a pipe. The equation describing foam flow in pipe can be obtained by modifying equation (8). The modification made includes: the suspension is considered to be made of foam only, the concentration of foam is one, the flow is downwards, and finally, the area open to flow is the entire cross-sectional of the pipe. For pipe flow, the drag force and material transfer in equation (8) are not considered.

$$
\frac{\partial\left(\rho_{f} u_{f}^{2}\right)}{\partial s}=-\frac{\partial p}{\partial s}+\rho_{f} g \operatorname{Cos} \theta-\frac{2 f_{f} \rho_{f} u_{f}^{2}}{D_{P}}
$$

The finite difference formulation of equation (A-47) is:

$P_{d p, i}=P_{d p, i+1}-\Delta \operatorname{sg} \operatorname{Cos} \theta \rho_{f, i+1}+\left(\frac{2 f_{f} \rho_{f} u_{f}^{2}}{D_{P}}\right)_{i+1}+\left(\rho_{f} u_{f}^{2}\right)_{i+1}-\left(\rho_{f} u_{f}^{2}\right)_{i}--\mathrm{A}-48$

$D_{p}$ is the diameter of the pipe open to flow. An iterative calculation procedure is required to solve equation (A-48).

\section{REFERENCES}

[1] Alberta Recommended Practices for Underbalanced Drilling, Interim Directive ID 94-3, Calgary, Canada, July, 1994.

[2] Wang, Z.; Rommetveit, R.; Bijleveld, A.; Maglione, R.; Gazaniol, D. Oil and Gas J., 1997, 95, 54-60.

[3] Bennion, D.B.; Thomas, F.B.; Bietz, R.F.; Bennion, D.W. SPE Drilling and Completion, 1998, 13, 214-221.

[4] Culen, M.S., Harthi, S.; Hashimi, H. A Direct Comparison Between Convention and Underbalanced Drilling Techniques in the Saih Rawl Field, Oman, Proceedings of the IADC/SPE Underbalanced Technology Conference and Exhibition, Houston, Texas, March 25-26, 2003.

[5] Negrao, A.F.; Lage, A.C.V.M.; Cunha, J.C. An Overview of Air/Gas/Foam Drilling in Brazil, SPE Drilling and Completion, 1999, 14, 109-114.

[6] Rojas, Y.; Vieira, P.; Borrell, M.; Blanco, J.; Ford, M.; Nieto, L.; Lopez, G.; Atencio, B. Field Application of Near-Balanced Drilling Using Aqueous Foams in Western Venezuela, Proceedings of the IADC/SPE Drilling Conference, Dallas, Texas, February 26-28, 2002.

[7] Jaramillo, M.; Bitterweed, S. A Case History in Changing Economics Using Underbalanced Drilling and Open Hole Completions, Proceedings of the IADC/SPE Drilling Conference, Houston, Texas, March 25-26, 2003.

[8] Lage, A.C.V.M.; Nakagawa, E.Y.; De Souza, A.A.; Santos, M.M. Recent Case Histories of Foam Drilling in Brazil, Proceedings of the 4th Latin American and Caribbean Petroleum Engineering Conference, Port-of-Spain, Trinidad \& Tobago, April 23-26, 1996.

[9] Hannegan, D.M.; Divine, R. Underbalanced Drilling -- Perceptions and Realities of Today's Technology in Offshore Applications, Proceedings of the IADC/SPE Drilling Conference, Dallas, Texas, February 26-28, 2002.

[10] Cade, R.; Kirvelis, R.; Nafta, M.; Jennings, J. Does Underbalanced Drilling Really Add Reserves? Proceedings of the IADC/SPE Drilling Conference, Houston, Texas, March 28-29, 2003.

[11] Park, D., Brand; P.R.; Allyson, B.; Sodersano, G. Planning and Implementation of the Repsol-YPF-MAXUS Krisna Underbalanced Drilling Project, Proceedings of the SPE/IADC Drilling Conference, Amsterdam, the Netherlands, February 27 - March 1, 2001.

[12] Mclennan, J.; Carden, R.S.; Curry, D.; Stone, C. R.; Wyman, R.E. Underbalanced Drilling Manual, Gas Research Institute, Chicago, Illinois, 1997.

[13] Meng, Y.F.; Lou, P.Y.; Jiao, D.; Lao, R.K.; Lao, H. Horizontal Well Technology with Cycling Using of Inert Foam, Proceedings of 
the SPE International Conference on Horizontal Well Technology, Calgary, Canada, November, 18-20, 1996.

[14] Kitsios, E.; Rovig J.; Reynolds, E. Underbalanced Drilling Through Oil Production Zones with Stable Foam In Oman, Proceedings of the IADC/SPE Drilling Conference, Dallas, Texas, February 15-18, 1994.

[15] Hall, D.L.; Roberts, R.D. Offshore Drilling with Preformed Stable Foam, Proceedings of the SPE California Regional Meeting, Long Beech, CA, April 11-13, 1984.

[16] Essary, R.L.; Rogers, E.E. Technique and results of Foam Redrilling Operations-San Joaquin Valley, California, Proceedings of the SPE symposium of formation damage control, Houston, TX, January 29-30, 1976.

[17] Bensten, N.W.; Veny, J.N. J. Pet. Technol., 1976, 28, p.1237-1240.

[18] Anderson, G.W. Use of preformed foam in lower pressure reservoir wells, Proceedings of the SPE $5^{\text {th }}$ off-shore South East Asia Conference, Singapore, February 21-24, 1984.

[19] Fraser I.M.; Moore R. H. Guidelines for Stable Foam Drilling through Permafrost, Proceedings of the SPE/IADC Drilling Conference, New-Orleans, LA, March 15-18, 1987.

[20] Frik, H. Horizontal Drilling In Low Pressure Reservoirs With A Foam Mud System, Proceedings of the DGMK spring Conference, Celle, Germany, April 27-28, 1995.

[21] Surewaard, J.; Kool, M.; Woodland, D.; Roed, H.; Hopmans, P. Approach to Underbalanced Well Operations in Petroleum Development Oman, Proceedings of the IADC/SPE Drilling Conference, New-Orleans, LA, U.S.A., March 12-15, 1996.

[22] Doane, R.D.; Bennion, D.B.; Eilers, D.M.; New, E.R. Successful Drilling of an Underbalanced Horizontal well in the Rigel Halfway Pool- Laboratory Screening and field Results, Proceedings of the SPE international Conference on Horizontal Well Technology, Calgary, Canada, November 18-20, 1996.

[23] Flak, K.; Mcdonald, C. An Overview of Underbalanced Drilling Application in Canada, Proceedings of the SPE European Formation Damage Conference, The Hague, The Netherlands, May 15$16,1995$.

[24] Scherschel, S.R.; Graves, D.G. Underbalanced - Directional Drilling with Coiled Tubing-Challenges and Solutions, Proceedings of the SPE International Conference on Horizontal Well Technology, Calgary, Canada, November 18-20, 1996.

[25] Nance, W. B.; Muncy, D.D.; Garrett, M.M.; Gault, A.D.; Kortlang Jr., W.F. A Comparative Analysis of Drilling Results Obtained with Oil Based Mud vs. Water-Based Mud at High Island Block A-270, Proceedings of the SPE/IADC Drilling Conference, New-Orleans, LA, February 20-23, 1983.

[26] Njerheim, A.; Tjotta, H. New World Record in Extended-Reach Drilling from Platform Statfjord ' $C$ ', Proceedings of the SPE/IADC Drilling Conference, New-Orleans, LA, February 18-21, 1993.

[27] Eck-Olsen, J.; Sletten, H.; Reynolds J.T.; Samuell, J.G. North Sea Advances in Extended-Reach Drilling, Proceedings of the SPE/IADC Drilling Conference, Amsterdam. February 23-25, 1993.

[28] Aarestad, T.V.; Blikra, H. Torque and Drag: Key Factors in Extended Reach Drilling, Proceedings of the SPE/IADC Drilling Conference, Dallas, February 15-18, 1994.

[29] Alfsen, T.E.; Heggen, S.; Tjotta, H. SPE Drilling and Completion, 1995, 71, 299.

[30] Tomren, P.H.; Iyoho, A.W.; Azar, J.J. SPE Drilling and Completion, 1986, 1, 43-56.

[31] Okrajni, S.S.; Azar, J.J. SPE Drilling and Completion, 1986, 1, p.297-308.

[32] Peden, J.M.; Ford, J.T.; Oyeneyin, M.B. Comprehensive Experimental Investigation of Drilled Cuttings Transport in Inclined Wells Including the Effects of Rotation and Eccentricity, Proceedings of the SPE/IADC Drilling Conference, The Hague, Netherlands, October 22-24, 1990.

[33] Larsen, T.I. Thesis, The University of Tulsa, 1990.

[34] Ford, J.T.; Peden, J.M.; Oyeneyin, M.B.; Gao, E.; Zarrough, R. Experimental Investigation of Drilled Cuttings Transport in Inclined Boreholes, Proceedings of the SPE 65th Annual Technical Conference and Exhibition, New Orleans, LA, September 23-26, 1990.

[35] Seeberger, M.H.; Matlock, R.W.; Hanson, P.M. Oil Muds in LargeDiameter, Highly Deviated Wells: Solving the Cuttings Removal Problem, Proceedings of the SPE/IADC Drilling Conference, New Orleans, LA, February 28- March 3, 1989.
[36] Brown, N.P.; Bern, P.A. Cleaning Deviated Holes; New Experimental and Theoretical Studies, Proceedings of the SPE/IADC Drilling Conference, New Orleans, LA, February 28- March 3, 1989.

[37] Becker, T.E.; Azar, J.J.; Okrajni, S.S. Correlations of Mud Rheological Properties with Cuttings Transport Performance in Directional Drilling, Proceedings of the SPE EUROPEC 90, The Hague, Netherlands, October 22-24, 1990.

[38] Stevenic, B.C. Thesis, The University of Tulsa, 1991.

[39] Sifferman, T.R.; Becker, T.E. SPE Drilling and Completion, 1992, 7, $115-120$.

[40] Jalukar, L.S. Thesis, The University of Tulsa, 1993.

[41] Hemphill, T.; Larsen, T.I. Hole-Cleaning Capabilities of Oil-Based and Water-Based Drilling Fluids: A Comparative Experimental Study, Proceedings of the SPE Annual Technical Conference and Exhibition, Houston, October, 3-6, 1993.

[42] Bassal, A.A. Thesis, The University of Tulsa, 1995.

[43] Martins, A.L; Sa, C.H.M.; Lourenco, A.M.F.; Freire, L.G.M.; Campos, W. Experimental Determination of Interfacial Friction Factor in Horizontal Drilling with a Bed of Cuttings, Proceedings of the $4^{\text {th }}$ Latin American and Caribbean Petroleum Engineering Conference, Port of Spain, Trinidad and Tobago, April 23-26, 1996.

[44] Luo, Y., Bern, P.A.; Chambers, B.D. Flow-Rate Prediction for Cleaning Deviated Wells, Proceedings of the IADC/SPE Drilling Conference, New Orleans, Louisiana, February 18-21, 1992.

[45] Larsen, T.I.; Pilehvari, A.A.; Azar, J.J. SPE Drilling and Completion, 1997, 12, p.129-135.

[46] Luo, Y.; Bern, P.A.; Chambers, B.D.; Kellingray, D. Simple Charts to Determine Hole Cleaning Requirements in Deviated Wells, Proceedings of the IADC/SPE Conference, Dallas, TX, U.S.A., 1994.

[47] Martins, A.L.; Santana, C.C. Evaluation of Cuttings Transport in Horizontal and Near Horizontal Wells - A Dimensionless Approach, Proceedings of the 2nd Latin American Petroleum Engineering, Caracas, Venezuela, March 8-11, 1992.

[48] Kenny, P.; Sunde, E.; Hemphill, T. Hole Cleaning Modeling: What's ' $n$ ' Got to Do with It?, Proceedings of the IADC/SPE Drilling Conference, New Orleans, LA, March 12-15, 1996.

[49] Martins, A.L; Sa, C.H.M.; Lourenco, A.M.F.; Freire; Campos, W. Optimizing Cuttings Circulation in Horizontal Well Drilling, Proceedings of the International Petroleum Conf., Villahermosa, Mexico, March 5-7, 1996.

[50] Zamora, M.; Hanson, P. Pet. Eng. Int., 1991, 63, 44-51.

[51] Zamora, M.; Hanson, P. Pet. Eng. Int., 1991, 63, 22-24.

[52] Rasi, M. Hole Cleaning in Large, High-Angle Wellbores, Proceedings of the IADC/SPE Drilling Conference, Dallas, TX, February 15-18, 1994.

[53] Gavignet, A.A.; Sobey, I.J. J. Pet. Technol., 1989, 41, 917-920.

[54] Kamp, A.M.; Rivero, M. Layer Modeling for Cuttings Transport in Highly Inclined Wellbores, Proceedings of the SPE Latin American and Caribbean Petroleum Conference, Caracas, Venezuela, April 21-23 1999.

[55] Clark, R.K.; Bickham, K.L. A Mechanistic Model for Cuttings Transport, Proceedings of the SPE 69th Annual Technical Conference and Exhibition, New Orleans, LA, September 25-28, 1994.

[56] Campos, W. Thesis, the University of Tulsa, 1995.

[57] Sanchez, A. Thesis, The University of Tulsa, 1997.

[58] Nguyen, D.; Rahman, S.S. A Three-Layer Hydraulic Program for Effective Cuttings Transport and Hole Cleaning in Highly Deviated and Horizontal Wells, Proceedings of the SPE SPE/IADC Asia Pacific Drilling Technology, Kuala Lumpur, Malaysia, September 9$11,1996$.

[59] Ford, J. Development of Mathematical Models Describing Drilled Cuttings Transport in Deviated Wells, Proceedings of the CADE / CAODC Spring Drilling Conference, Calgary, AB, April 14-16, 1993.

[60] Ozbayoglu, E.M.; Miska, S.Z.; Reed, T.; Takach, N. Cuttings Transport with Foam in Horizontal \& Highly-Inclined Wellbore, Proceedings of the SPE/IADC Drilling Conference, Amsterdam, The Netherlands, February 19-21, 2003.

[61] Kelessidis, V. C.; Mpanelis, G.E. Flow Pattern and Minimum Suspension Velocity For Efficient Cuttings Transport in Horizontal and Deviated Well in Coiled-Tubing Drilling, Proceedings of the SPE/ICoTA Coiled Tubing Drilling Conference, Houston, TX, U.S.A., April 8-9, 2003. 
[62] Doan, Q.T.; Oguztoreli, M.; Masuda, Y.; Yonezawa, T.; Kobayashi, A.; Kamp, A. SPE J., 2003, 8, 160-170.

[63] Krug, J.A.; Mitchell, B.J. Oil \& Gas J., 1972, 70, 35-40.

[64] Okpobiri, G.A.; Ikoku, C.U. SPE Drilling and Completion, 1986, 1, p.71-86.

[65] Owayed, J.F. Thesis, The University of Tulsa, 1997.

[66] Li, Y. Thesis, University of Alberta, 2004.

[67] Guo, B.; Miska, S.; Hareland, G. A Simple Approach to Determination of Bottom Hole Pressure in Directional Foam Drilling, Proceedings of the ASME Drilling Technology Symposium, New Orleans, LA, 1995.

[68] Doron, P.; Granica, D.; Barnea, D. Int. J. Multiphase Flow, 1987, 13, 535-547.

[69] Wilson, K.C. A Unified Physically Based Analysis of Solid-Liquid Pipeline Flow, Proceedings of the $4^{\text {th }}$ Int. Conf. On Hydraulic Transport of Solids in Pipes, Banff, Alberta, Canada, 1976.

[70] Shook, C.A.; Gillies, R.; Haas, D.B.; Husband, W.H.W.; Small, M. J. Pipelines, 1982, 3, 13-21.

[71] Crowe, C.T. Multiphase Flow with Droplets and Particles, CRC press, Boca Rotan, Florida, 1998.

[72] Patankar, S.V. Numerical Heat Transfer and Heat Flow, Hemisphere Publishing Corporation: New York, 1980.

[73] Capo, J. Thesis, The University of Tulsa, 2003.

[74] Yarborough, L.; Hall, K.R. Oil Gas J., 1974, 72, 86-88.

[75] Raza, S.H.; Marsden, S.S. SPE J., 1967, 7, 359-368.

[76] David, A.; Marsden, S. The Rheology of Foam, Proceedings of the SPE Annual Fall Meeting, Denver, Colorado, September 28 - October 1,1969

[77] Enzendorfer, C.; Harris, R.; Valko, P.; Economides, M. J. Rheol., 1995, 39, 345-358.

[78] Sanghani, V.; Ikoku, C.U. J. Energy Res. Technol., 1983, 105, 362371.

[79] Harris, P.C.; Reidenbach, V.G. J. Pet.Technol., 1987, 39, 613-619.

[80] Mitchell, B.J. Thesis, University of Oklahoma, 1969.

[81] Beyer, A.H.; Millhone, R.S.; Foote, R.W. Flow Behavior of Foam as A Well Circulating Fluid, Proceedings of the $47^{\text {th }}$ Annual Fall Meeting of the Society of Petroleum Engineers of AIME, San Antonio, TX., October 8-11, 1972.

[82] Blauer, R.E.; Mitchel, B.J.; Kohllhaas, C.A. Determination of Laminar, Turbulent, and Transitional Foam Flow Losses in Pipes, Proceedings of the SPE Annual California Regional Meeting, San Francisco, California, April 4-5, 1974.
[83] Reidenbach, V.G.; Harris, P.C.; Lee, Y.N.; Lord, D.L. SPE Production and Facilities Engineering, 1986, 1, 31-41.

[84] Bonilla, L.F.; Shah, S.N. Experimental Investigation on the Rheology of Foams, Proceedings of the SPE/CERI Gas Technology Symposium, Calgary, Alberta, Canada, April 3-5, 2000.

[85] Ozbayoglu, E.; Kuru, E.; Miska, S.; Takach, N. J. Can. Pet. Technol., 2002, 41, 52-61.

[86] Clift, R. Bubbles, Drops, and Particles, Academic Press: New York, 1978.

[87] Bird, R. B.; Stewart, W. E.; Lightfoot, E. N. Transport Phenomena, John Wiley \& Sons Inc.: New York, 1960, pp. 56-60 and 19094.

[88] Sharma, M. K.; Chhabra, R. P. Chem. Eng. Process, 1991, 30, 6167.

[89] Dedegil, M.Y. J. Fluids Eng., 1987, 109, 14-21.

[90] Shah, S.N. SPE J., 1982, 22, 164-170.

[91] Fang, G. Experimental Study of Free Settling of Cuttings in Newtonian and Non-Newtonian Drillings Fluids: Drag Coefficient and Settling Velocity, Society of Petroleum Engineers data bank, Paper No: SPE 26125, 1992

[92] Peden, J.M.; Luo, Y. SPE Drilling Eng., 1987, 2, 337-343.

[93] Acharya, R.A.; Ulbrecht, J. RHEOL. Acta, 1979, 15, 454.

[94] Darby, R. Chem. Eng., 1996, 103, 109.

[95] Matijasic, G.; Glasnovic, A. Chem. Biochem. Eng. Quart., 2001, $15,21$.

[96] Chhabra, R. P. Sedimentation of particles in non-Newtonian media, Department of Chemical Engineering, Indian Institute of Technology, India, 2002

[97] Chien, S.F. SPE Drilling and Completion, 1994, 9, 281-289.

[98] Konno, H.; Saito, S. J. Chem. Eng. Jpn., 1969, 2, 211-217.

[99] Capes, C.A.; Nakamura, K. Can. J. Chem. Eng., 1973, 51, 31-38.

[100] Yang, W.C. AICHE J., 1978, 24, 548-552.

[101] Tulay, A.; Ozbelge Int. J. Multiphase Flow, 1984, 10, 459-465.

[102] Skelland, A.H.P. Non-Newtonian Flow and Heat Transfer, John Wiley and Sons, Inc.: New York, 1967.

[103] Fredrickson, A.G.; Bird, R.B. Ind. Eng. Chem., 1958, 50, 347-52.

[104] Fredrickson, A.G.; Bird, R.B. Ind. Eng. Chem., 1958, 50, 15991600.

[105] Bagnold, R. A. Proc. R. Soc., 1954, A225, 49-63.

[106] Bagnold, R. A. Phil. Trans. R. Soc., 1957, A249, 235-297.

[107] Wilson, K. C. Proc. ASCE, J. Hydraul. Div., 1970, 96, 1-12.

[108] Gadala-Maria, F.A. Thesis, Stanford University, 1979.

[109] Leighton, D.; Acrivos, A. Chem. Eng. Sci., 1986, 41, 1377-1384.

(C) Osunde and Kuru; Licensee Bentham Open.

This is an open access article licensed under the terms of the Creative Commons Attribution Non-Commercial License (http://creativecommons.org/licenses/by$\mathrm{nc} / 3.0 /$ /)/ which permits unrestricted, non-commercial use, distribution and reproduction in any medium, provided the work is properly cited. 